\title{
EL ENFOQUE DE DERECHOS HUMANOS Y LA PROTECCIÓN DE LOS GRUPOS VULNERABLES EN LA POLÍTICA MIGRATORIA Y EL ORDENAMIENTO JURÍDICO DEL ESTADO PERUANO
}

\author{
THE HUMAN RIGHTS APPROACH AND THE PROTECTION OF \\ VULNERABLE GROUPS IN THE MIGRATION POLICY AND THE \\ LEGAL ORDER OF PERUVIAN STATE
}

\author{
Rafael Rodríguez Campos* \\ Katia Vega Bendezú ${ }^{* *}$
}

\section{Resumen:}

Sirva este artículo para exponer algunos apuntes institucionales, doctrinarios, normativos y jurisprudenciales sobre la incorporación del Enfoque de Derechos Humanos y la Protección de los Grupos Vulnerables, en la Política Migratoria y el Ordenamiento Jurídico del Estado peruano, para luego, reflexionar sobre el deber del Estado peruano de adecuar el sistema jurídico a los Derechos Humanos; e informar, finalmente, sobre la presencia del Enfoque de Derechos Humanos y la Protección de los Grupos Vulnerables en las acciones implementadas por la Superintendencia Nacional de Migraciones, debiendo señalar que haremos una mención particular a la protección de los niños, niñas y adolescentes migrantes por ser un Grupo Vulnerable que requiere una especial protección.

Palabras clave: Política Nacional Migratoria, enfoque de derechos humanos y protección de grupos vulnerables.

\section{Abstract:}

This article presents some institutional, doctrinal, normative and jurisprudential

Asesor en la Gerencia de Política Migratoria de la Superintendencia Nacional de Migraciones. Abogado por la Pontificia Universidad Católica del Perú (PUCP). Cuenta con un título de posgrado y estudios de maestría en Ciencia Política y Gobierno en la Escuela de Gobierno y Políticas Públicas de la PUCP. Cuenta con un título de especialista en Justicia Constitucional, Interpretación y Aplicación de la Constitución en la Universidad Castilla - La Mancha (Toledo - España). Es candidato a máster en Derecho Constitucional en la Universidad Castilla - La Mancha (Toledo-España). Es miembro de la Asociación Peruana de Derecho Constitucional. Ha sido profesor de Derecho Electoral y Ciencia Política en la Facultad de Derecho de la Universidad de San Martín de Porres (USMP). Es profesor de Historia de las Ideas Políticas en la Facultad de Derecho de la USMP.

** Responsable del Equipo de Integración Migratoria de la Gerencia de Política Migratoria de la Superintendencia Nacional de Migraciones. Licenciada en Historia por la Universidad Nacional San Cristóbal de Huamanga. Cuenta con un título de posgrado y estudios de maestría en Gerencia Social en la Escuela de Posgrado de la Pontificia Universidad Católica del Perú (PUCP). Cuenta con una experiencia de más de 20 años en cargos directivos en áreas de Gestión Social, Identificación, Registro y Migración con manejo y aplicación de Enfoques de Derechos Humanos, Niñez, Género e Interculturalidad. Asimismo, ha participado en el impulso, formulación y monitoreo de nuevos procesos, planes y proyectos sociales de impacto nacional. 
notes about the incorporation of the Human Rights Approach and the Protection of Vulnerable Groups, in the Migration Policy and the Legal Order in Peru; a reflection on the duty of the Peruvian State to adapt the legal system to human rights; and finally report the presence of the Human Rights Approach and the Protection of Vulnerable Groups in the actions implemented by the National Superintendency of Migration, also referring a particular mention on migrant children and adolescents as a Vulnerable Group which requires special protection.

Keywords: National Migration Policy, Human Rights, approach and protection of vulnerable groups.

\section{INTRODUCCIÓN}

En un artículo titulado "Si tú no emigraste, emigró tu padre: José Saramago sobre la inmigración", publicado el 23 de octubre de 2018, se recuerda que la historia del ser humano es indisociable de la migración, ya que desde nuestros orígenes como especie hasta las noticias que nos llegan esta mañana, los flujos migratorios humanos no se han detenido nunca: decenas, cientos o miles de personas salen a cada momento del lugar donde nacieron para dirigirse a otro punto, en apariencia por razones diversas pero, en el fondo, por un único motivo: la búsqueda de bienestar.

A propósito, consideramos oportuno reproducir un fragmento del texto titulado "Historias de la Migración", elaborado por José Saramago, Premio Nobel de Literatura en 1998, publicado en el blog que tuvo en los últimos años de su vida, pues aborda, en nuestra opinión, dos temas fundamentales a propósito de la migración: La Integración y el Respeto de los Derechos Humanos de los Migrantes:

Que tire la primera piedra quien nunca haya tenido manchas de emigración ensuciándole el árbol genealógico. Tal como en la fábula del lobo malo que acusaba al inocente corderito de enturbiarle el agua del riachuelo donde ambos bebían, si tú no emigraste, emigró tu padre, y si tu padre no necesitó mudar de sitio fue porque tu abuelo, antes que él, no tuvo otro remedio que irse, cargando la vida sobre las espaldas, en busca del pan que su tierra le negaba. Muchos portugueses murieron ahogados en el río Bidasoa cuando, noche oscura, intentaban alcanzar a nado la orilla de allá, donde se decía que el paraíso de Francia comenzaba. Centenares de miles de portugueses tuvieron que someterse, en la llamada culta y civilizada Europa de más allá de los Pirineos, a condiciones de trabajo infames y a salarios indignos. Los que consiguieron soportar las violencias de siempre y las nuevas privaciones, los sobrevivientes, desorientados en medio de sociedades que los despreciaban y humillaban, perdidos en idiomas que no podian entender, fueron a poco a poco construyendo, con renuncias y 
sacrificios casi heroicos, moneda a moneda, centavo a centavo, el futuro de sus descendientes. Algunos de esos hombres, algunas de esas mujeres, no perdieron ni quieren perder la memoria del tiempo en que tuvieron que padecer todos los vejámenes del trabajo mal pagado y todas las amarguras del aislamiento social. Gracias les sean dadas por haber sido capaces de preservar el respeto que debian a su pasado. Otros muchos, la mayoría, cortaron los puentes que los unían a las horas sombrías, se avergonzaron de haber sido ignorantes, pobres, a veces miserables, se comportan, en fin, como si una vida decente, para ellos, sólo hubiese comenzado verdaderamente el día felicísimo en que pudieron comprar su primer automóvil. Esos son los que estarán siempre dispuestos a tratar con idéntica crueldad e idéntico desprecio a los emigrantes que atraviesan ese otro Bidasoa, más ancho y más hondo, que es el Mediterráneo, donde los ahogados abundan y sirven de pasto a los peces, si la marea y el viento no prefieren empujarlos hasta la playa, mientras la guardia civil no aparece para levantar los cadáveres. Los sobrevivientes de los nuevos naufragios, los que pusieron pie en tierra y no fueron expulsados, tendrán a su espera el eterno calvario de la explotación, de la intolerancia, del racismo, del odio por su piel, de la sospecha, de la humillación moral. El que antes había sido explotado y perdió la memoria de haberlo sido, explotará. El que fue despreciado y finge haberlo olvidado, afinará su propia manera de despreciar. Al que ayer humillaron, humillará hoy con más rencor. $Y$ ahí están, todos juntos, tirándoles piedras al que llega a la orilla de acá de este Bidasoa, como si nunca hubiesen emigrado ellos, o los padres, o los abuelos, como si nunca hubiesen sufrido de hambre y de desesperación, de angustia y de miedo. En verdad, en verdad os digo, hay ciertas maneras de ser feliz que son simplemente odiosas". (Saramago, J., 2009, viernes 17 de julio)

Hemos creído importante hacer esta referencia al pensamiento de José Saramago porque nos permite introducirnos al estudio del tema propuesto en este artículo: “El Enfoque de Derechos Humanos y la Protección de los Grupos Vulnerables en la Política Migratoria y el Ordenamiento Jurídico del Estado peruano", debiendo señalar que haremos una mención particular a la protección de los niños, niñas y adolescentes migrantes (en adelante, NNA migrantes), por ser un Grupo Vulnerable que requiere una especial protección.

\section{ANÁLISIS}

Alrespecto,estimamosoportunoexponeralgunosapuntesinstitucionales, doctrinarios, normativos y jurisprudenciales sobre la incorporación del Enfoque de Derechos Humanos y la Protección de los Grupos Vulnerables, en la Política Migratoria y el Ordenamiento Jurídico del Estado peruano, para luego, reflexionar sobre el deber del Estado peruano de adecuar el sistema jurídico a los Derechos Humanos; e informar, finalmente, sobre la presencia del Enfoque de Derechos Humanos y la Protección de los Grupos Vulnerables 
(NNA migrantes, especialmente) en las acciones implementadas por la Superintendencia Nacional de Migraciones (en adelante, MIGRACIONES).

2.1 Apuntes Institucionales sobre la incorporación del Enfoque de Derechos Humanos y la Protección de los Grupos Vulnerables en la Política Migratoria y el Ordenamiento Jurídico del Estado peruano

\section{a. Sobre las Políticas Nacionales y Políticas Sectoriales}

El artículo $4^{\circ}$ de la Ley $N^{\circ} 29158$, Ley Orgánica del Poder Ejecutivo, establece como una de sus competencias exclusivas el diseño y supervisión de las políticas nacionales y sectoriales, las cuales son de cumplimiento obligatorio para todas las entidades del Estado en todos los niveles de gobierno.

Mediantelas Políticas Nacionales seestablecenlos objetivos prioritarios, los lineamientos, los contenidos principales de las políticas públicas, los estándares nacionales de cumplimiento y la provisión de servicios que deben ser alcanzados y supervisados para asegurar el normal desarrollo de las actividades públicas y privadas; las mismas que conforman la Política General de Gobierno y se aprueban mediante Decreto Supremo, con el voto del Consejo de Ministros.

Al mismo tiempo, el artículo $4^{\circ}$ de la citada Ley $\mathrm{N}^{\circ} 29158$, distingue las políticas nacionales de las sectoriales, señalando que estas últimas están referidas a un aspecto de la política nacional que afecta una actividad económica y social específica pública o privada.

A su turno, el artículo $22^{\circ}$ de la precitada Ley $\mathrm{N}^{\circ} 29158$, estipula que los ministerios diseñan, establecen, ejecutan y supervisan las políticas nacionales y sectoriales, asumiendo la rectoría respecto de ellas. De igual modo, su artículo $23^{\circ}$ refiere que los ministerios formulan, planean, dirigen, coordinan, ejecutan, supervisan y evalúan la política nacional y sectorial bajo su competencia.

\section{b. Sobre el Ministerio del Interior y la Política Sectorial Migratoria Interna}

La Ley de Organización y Funciones del Ministerio del Interior, Decreto Legislativo $\mathrm{N}^{\circ}$ 1266, establece que dicho sector formula, dirige, coordina y evalúa el registro y los servicios migratorios, disponiendo de forma específica en el artículo $5^{\circ}$ que tiene a su cargo supervisar y evaluar el cumplimiento de las políticas en 
materia migratoria interna.

En esa línea, el Decreto Legislativo $N^{\circ}$ 1350, Decreto Legislativo de Migraciones, incorpora en su Título Preliminar el Principio de Integralidad mediante el cual el Estado promueve el tratamiento integral del fenómeno migratorio en consideración a su complejidad e impactos transversales, que requieren una respuesta intersectorial, multidimensional y de corresponsabilidades.

Por su parte, el artículo $4^{\circ}$ del citado Decreto Legislativo $\mathrm{N}^{\circ} 1350$, define que el Poder Ejecutivo dicta la Política Migratoria en los ámbitos externo e interno, la misma que forma parte de la Política de Estado. Este artículo precisa también que, en el ámbito interno, la Política Migratoria se orienta a determinar la relación del Estado Peruano para efectos del ingreso, permanencia, residencia y salida del territorio peruano de personas nacionales y extranjeras; $y$, en el ámbito externo, a la protección y asistencia de connacionales en el exterior y a la relación con las y los nacionales de otros Estados, en el marco de las relaciones internacionales.

\section{c. Sobre MIGRACIONES y la Política Sectorial Migratoria Interna a cargo del Ministerio del Interior}

El artículo $1^{\circ}$ del Decreto Legislativo $N^{\circ} 1130$, Decreto Legislativo que crea a MIGRACIONES, establece que se trata de un Organismo Técnico Especializado adscrito al Ministerio del Interior, con personería jurídica de derecho público interno, con autonomía administrativa, funcional y económica en el ejercicio de sus atribuciones.

Asimismo, el artículo $2^{\circ}$ del referido Decreto Legislativo señala que MIGRACIONES tiene competencia en materia de política migratoria interna y participa en la política de seguridad interna y fronteriza. Además, coordina el control migratorio con las diversas entidades del Estado que tengan presencia en los Puestos de Control Migratorio o Fronterizo del país para su adecuado funcionamiento; y tiene competencia de alcance nacional.

Por su parte, el artículo $6^{\circ}$ del mismo Decreto Legislativo, dispone que MIGRACIONES tiene, entre otras, las siguientes funciones: a) Proponer la Política Sectorial en el ámbito de su competencia; y b) Ejecutar la política migratoria interna, en el marco de su competencia y de conformidad con la normatividad y los tratados internacionales, 
promoviendo la integración de las personas migrantes a la sociedad peruana.

En ese sentido, queda claro que la Política Sectorial Migratoria Interna del Estado Peruano, según el marco normativo antes mencionado, tiene al Ministerio del Interior como entidad rectora, siempre apoyado por su Organismo Técnico Especializado adscrito al sector: MIGRACIONES.

\section{d. Sobre la Política Nacional Migratoria y la Política Sectorial Migratoria Interna}

El Decreto Supremo $N^{\circ}$ 067-2011-PCM, en su artículo $1^{\circ}$, creó la Comisión Multisectorial Permanente denominada "Mesa de Trabajo Intersectorial para la Gestión Migratoria (MTIGM), adscrita al Ministerio de Relaciones Exteriores, con el objeto de coordinar, evaluar, proponer, priorizar y supervisar políticas y acciones vinculadas a la gestión integral migratoria.

Luego, mediante Decreto Supremo $\mathrm{N}^{\circ}$ 015-2017-RE, publicado el 27 de abril de 2017 en el Diario Oficial El Peruano, se aprobó la Política Nacional Migratoria 2017-2025 (en adelante, Política Nacional Migratoria), señalando que la misma es de cumplimiento obligatorio por todas las entidades del Estado a todos los niveles de gobierno, acorde con el ámbito de sus competencias y funciones. Es importante señalar que esta Política Nacional fue elaborada en el marco de la MTIGM.

En ese marco, y por las propias características del proceso migratorio, que en palabras de la Organización Internacional para las Migraciones (en adelante, OIM), son complejos debido a la multiplicidad de causas que impulsan estos procesos, sus diversas etapas, la variedad de actores públicos y privados relacionados, sus impactos, los derechos comprometidos, y los diversos roles que un mismo Estado tiene respecto a su gestión, es importante que la gestión migratoria estatal responda de manera intersectorial ante las diversas demandas, expectativas y necesidades de los Cuatro Ejes de Trabajo identificados por la MTIGM: 1) Peruanos y peruanos con voluntad de migrar; 2) Población peruana que vive en el exterior; 3 ) Connacionales que retornan al Perú; y 4) Población extranjera que ha escogido al Perú como un país de tránsito o destino.

Sobre el particular, estimamos necesario subrayar la importancia del 
Eje de Trabajo 4) Población extranjera que ha escogido al Perú como un país de tránsito o destino; ya que la Política Sectorial Migratoria Interna del Estado peruano, que tiene, como ya lo hemos señalado, al Ministerio del Interior como entidad rectora, apoyado por su Organismo Técnico Especializado adscrito al sector:MIGRACIONES, debe centrarse únicamente en este grupo poblacional.

Ahora bien, tomando como referencia lo expresamente señalado en la Política Nacional Migratoria, estimamos necesario exponer cinco grandes ideas que, sobre todo desde 2017, marcan el rumbo de la gestión migratoria integral en el Perú:

Primera: la Constitución Política del Perú (en adelante, Constitución), establece las directrices en materia de política migratoria que parten del reconocimiento de "la defensa de la persona humana y el respeto de su dignidad como el fin supremo de la sociedad y del Estado" y de que toda persona tiene derecho a "la igualdad ante la ley. Nadie debe ser discriminado por motivo de origen, raza, sexo, idioma, religión, opinión, condición económica o de cualquiera otra índole" y a "elegir su lugar de residencia, transitar por el territorio nacional y salir de él y entrar en él, salvo limitaciones por razones de sanidad o por mandato judicial o por aplicación de la ley de extranjería", a la luz de lo señalado en el artículo $1^{\circ}$ y en los numerales 2 y 11 del artículo $2^{\circ}$, respectivamente, de la Carta Política.

Segunda: el Estado peruano ha suscrito los principales instrumentos universales y regionales sobre derechos humanos, especialmente, la Convención Internacional para la Protección de los Derechos de todos los Trabajadores Migrantes y sus Familias, incorporados al ordenamiento jurídico nacional, de conformidad con el artículo $55^{\circ}$ de la Constitución.

Asimismo, la Cuarta Disposición Final y Transitoria de la Carta Política señala que los tratados ratificados y vigentes sobre derechos humanos forman parte del derecho nacional y se constituyen en parámetro de interpretación obligatoria de los derechos y libertades constitucionalmente reconocidos. Por ello, el Perú viene desplegandosu Política Nacional Migratoria en el marco de un certero respeto y cumplimiento de estos tratados, habiendo incorporado progresivamente en el proceso de elaboración y coordinación de las políticas públicas el Enfoque de Derechos humanos.

Tercera: el Estado peruano considera que la migración debe 
desarrollarse en un marco de observancia de los tratados y acuerdos internacionales, la normativa interna y el respeto de nuestra soberanía. Asimismo, reconoce que es un proceso que contribuye con el desarrollo de las personas que migran, sus familias, el Perú y la sociedad en general.

Cuarta: la Política Nacional Migratoria busca articular a las diversas instancias públicas y de la sociedad para responder adecuadamente a los desafíos migratorios en estricto cumplimiento de los principios de respeto de los derechos humanos; no discriminación; no criminalización del proceso migratorio; promoción de una movilidad informada, ordenada, segura y respetuosa de la soberanía nacional. Asimismo, se considera también que la gestión migratoria debe realizarse en el marco de la igualdad, la equidad, la inclusión, la integración y la seguridad nacional.

Quinta: el Estado peruano asume la responsabilidad de generar el mayor conocimiento sobre los diversos procesos migratorios, en particular, desarrollar diagnósticos adecuados que analicen de manera diferenciada las realidades de la población migrante teniendo en cuenta el género, la edad y otras condiciones y particularidades; y, a partir de ello, transferir competencias y experticias en todos los niveles de gobierno (nacional, regional y local) para que se involucren activamente en el diseño y ejecución de políticas migratorias que efectivamente respondan a los intereses, necesidades y demandas de las mujeres y los hombres migrantes

En esa misma línea, es importante reiterar que el Estado peruano, ha incorporado progresivamente el Enfoque de Derechos Humanos, el mismo que guarda estricta relación con el contenido y alcances de la Política Nacional Migratoria.

Así, por ejemplo, el Estado peruano reconoció en 2017 que los problemas de la población extranjera que ha escogido al Perú como un país de tránsito o destino están asociados a la protección de sus derechos y a su inclusión social y productiva en el Perú, respetando su identidad cultural y sin perder su vinculación con sus países de origen. Además, reconoció que las políticas migratorias no eran suficientes, o en todo caso, estaban desfasadas, situación que desde 2017, sobre todo, viene siendo resuelta progresivamente por las entidades públicas vinculadas a la gestión migratoria integral.

Asimismo, el Estado peruano declaró que existe una estigmatización 
hacia la persona inmigrante. Esto hace que, muchas veces, la población extranjera en el Perú sea considerada como infractora o como grupos de riesgo para la seguridad ciudadana y/o la moral pública (asociación migración femenina y prostitución, por ejemplo). En ese marco, por ejemplo, se configuran situaciones de discriminación y de violencia familiar y/o sexual en donde la condición de migrante irregular incrementa el grado de vulnerabilidad de estas personas, $y$, por ende, el Estado debe adoptar las acciones que correspondan para cambiar progresivamente esta situación.

Además, es necesario destacar que la Política Nacional Migratoria, además de haber incorporado en su base el Enfoque de Derechos Humanos, ha hecho lo propio con otros Enfoques que optimizan y concretizan al primero:

1) Enfoque de Inclusión Social: su desarrollo es progresivo y gradual, y fomenta el ejercicio pleno de derechos de las y los migrantes, considerando inicialmente, la regularización migratoria y la residencia hasta garantizar el ejercicio de una ciudadanía y la transformación de la persona migrante como agente de desarrollo tanto en la sociedad de origen, como la de destino, a través del acceso a todos los derechos y servicios, teniendo especial consideración a las poblaciones más vulnerables.

2) Enfoque de Integralidad: considera al proceso migratorio como una unidad que se inicia con el deseo o necesidad de salir del país, y culmina con la integración al país de acogida o retorno. En ese marco, tiene en cuenta las diversas características y condiciones de las personas que se movilizan, la multiplicidad de causas que impulsan la movilidad -sean estructurales o coyunturales y los impactos que este proceso tiene en la vida del migrante y las sociedades de origen, tránsito y destino, especialmente en una dimensión económica, política, social y cultural.

3) Enfoque Intersectorial e Intergubernamental: las políticas migratorias forman parte de una visión integradora de políticas nacionales, sectoriales, regionales y locales, y su implementación se desarrolla en los procesos de la gestión pública de cada uno de dichos niveles de gobierno, conforme a sus autonomías y competencias. La Política Nacional también se articula con las políticas internacionales en materia migratoria, coadyuvando a la consolidación de procesos de integración internacional. 
4) Enfoque de protección, asistencia y orientación al migrante: busca disminuir las condiciones de vulnerabilidad de la persona migrante. En ese sentido, promueve la eficiencia de los servicios administrativos que se brindan a peruanos, peruanas y población extranjera con el objetivo de promover procesos migratorios informados y seguros.

5) Enfoque Intercultural: parte del reconocimiento de las diferencias culturales como uno de los pilares de la construcción de una sociedad democrática, fundamentada en el establecimiento de relaciones de equidad e igualdad de oportunidades y derechos, implica que el Estado valorice e incorpore las diferentes visiones culturales, concepciones de bienestar y desarrollo de los diversos grupos étnico-culturales para la generación de servicios con pertinencia cultural, la promoción de una ciudadanía intercultural basada en el diálogo y la atención diferenciada a los pueblos indígenas y la población afrodescendiente.

6) Enfoque de Género: permite analizar el proceso de migración de hombres y mujeres desde las consideraciones de género que influyen en las causas, las consecuencias y en la experiencia migratoria propiamente dicha, en cada una de sus etapas; es decir, analiza las vías y redes para migrar, las oportunidades, los lugares de destino; las relaciones con el país de origen; los riesgos, las vulnerabilidades y las necesidades que afrontan; los roles, las expectativas, relaciones y dinámicas de poder que se desarrollan, en el país de origen y de destino, entre otros aspectos.

Del mismo modo, es importante mencionar que para la identificación de las propuestas de solución para el fenómeno migratorio que fueran incorporadas a los lineamientos de la Política Nacional Migratoria, se han establecido los siguientes principios, los mismos que también están directamente vinculados con el Enfoque de Derechos Humanos que inspira la gestión migratoria del Estado peruano:

1) Respeto por los Derechos Humanos de todas las personas migrantes y sus familias, en cumplimiento de los compromisos asumidos por el Perú mediante la suscripción de tratados internacionales sobre la materia.

2) Igualdad y No Discriminación de las personas migrantes, promoviendo su inclusión social y productiva; así como, la prevención y sanción de toda manifestación de violencia, xenofobia y racismo hacia las personas migrantes. 
3) No criminalización de la persona migrante, especialmente de aquella que se encuentra en situación migratoria irregular, de conformidad con los tratados internacionales ratificados por el Perú.

4) Promoción de una movilidad internacional informada, ordenada y segura, respetuosa de la soberanía y normativa interna.

5) Reconocimiento del aporte de los migrantes al desarrollo social, político, económico y cultural de los países de origen, tránsito y destino.

6) Gobernanza migratoria como un factor que articula entre sí las políticas, procesos y actores nacionales e internacionales, con el objeto de atender los desafíos de la migración internacional, tomando en cuenta que los esfuerzos deben relacionar el trabajo conjunto de los Estados, las estrategias de cooperación internacional, el aporte de los organismos internacionales, organizaciones de la sociedad civil y demás actores vinculados a la temática.

7) Protección del interés superior de la niña, el niño y el adolescente y de la unidad familiar en toda la intervención del Estado en materia migratoria.

Por lo antes expuesto, es posible afirmar que el Estado peruano -sobre todo a partir de 2017-viene realizando enormes esfuerzos por contar con herramientas institucionales que le permitan alcanzar el objetivo central de su Política Nacional Migratoria, la misma que ha sido elaborada con Enfoque de Derechos Humanos, y que se resume en lo siguiente: "Garantizar el respeto y protección de los derechos de las personas migrantes, promoviendo la igualdad, la equidad, la inclusión, la integración y la observancia de la seguridad nacional, a través de una eficiente gestión integral del proceso migratorio que articule al Estado y a la Sociedad, acorde a las necesidades, intereses y expectativas de la población migrante y sus familiares".

Del mismo modo, estimamos oportuno recordar que el centro de la Política Sectorial Migratoria Interna es el eje temático 4) Población extranjera que ha escogido al Perú como un país de tránsito o destino, identificado por la MTIGM. Cabe precisar que el Estado peruano, en su Política Sectorial Migratoria Interna, también ha incorporado el Enfoque de Derechos Humanos, así como los Enfoques y Principios de la Política Nacional Migratoria, lo que 
progresivamente ha permitido:

- Promover la integración del migrante en la sociedad peruana en el marco de respeto de sus derechos.

- Reforzar la seguridad interna y en fronteras que permitan reducir los riesgos a fin de evitar el ingreso y salida de personas extranjeras que puedan atentar contra el orden interno, la seguridad nacional y la soberanía de nuestro territorio.

- Promover el aporte productivo e intelectual del migrante al desarrollo del país.

Además, si uno revisa el marco normativo e institucional vigente, podrá identificar que las acciones adoptadas por el Estado peruano responden a una Política Sectorial Migratoria Interna, diseñada con Enfoque de Derechos Humanos, inspirada en los siguientes lineamientos:

- Fortalecer acciones de prevención, investigación y sanción contra toda forma de violencia, en especial la violencia de género, discriminación, xenofobia y racismo hacia la población migrante.

- Desarrollar acciones que garanticen el acceso a la educación, salud y servicios sociales a la persona migrante extranjera en el Perú, sin importar su condición jurídica migratoria.

- Respetar la identidad nacional de la población migrante extranjera, y fomentar acciones de intercambio social, económico y cultural.

- Establecer mecanismos y acciones que garanticen una atención oportuna, articulada y sostenida a personas en situación de especial vulnerabilidad y a personas que requieren protección internacional.

- Canalizar las capacidades de la inmigración calificada en el Perú, a fin de que cooperen con el desarrollo y la integración nacional.

Por último, atendiendo a lo antes expuesto, es posible afirmar que el Estado peruano -sobre todo a partir de 2017- viene realizando enormes esfuerzos por contar con herramientas institucionales que le permitan alcanzar el objetivo central de su Política Sectorial Migratoria Interna, la misma que ha sido elaborada con Enfoque de Derechos Humanos, y que se 
resume en lo siguiente: "Respetar los derechos humanos de los migrantes en armonía con el orden interno, la seguridad nacional y la soberanía de nuestro país, buscando una eficiente gestión migratoria que permita la plena integración e inclusión social del migrante buscando su contribución al desarrollo de capacidades del país".

\section{e. Plan Nacional de Derechos Humanos (2018-2021)}

Por último, una mención especial merece el Tercer Plan Nacional de Derechos Humanos 2018-2021 (los dos primeros fueron los vigentes en los periodos 2006-2011 y 2014-2016, respectivamente), elaborado conjuntamente por todos los sectores del Poder Ejecutivo bajo la coordinación del Ministerio de Justicia y Derechos Humanos, con participación de la sociedad civil, el mismo que se ha visto enriquecido en diversos aspectos fundamentales. El primero ha sido, sin lugar a dudas, la mayor presencia de las entidades del Poder Ejecutivo y del Estado en general, cuyos funcionarios y funcionarias han demostrado un alto sentido del deber. La participación de cada uno de ellos ha puesto de manifiesto que el enfoque basado en derechos humanos está siendo, cada vez, más internalizado en su labor diaria.

Este documento realiza un diagnóstico serio de la situación real y actual de los derechos humanos en el Perú, para culminar con el establecimiento integral de lineamientos estratégicos, objetivos, metas y actividades previstas: 1) Promoción de una Cultura de Derechos Humanos y la Paz; 2) Diseño y fortalecimiento de la Política Pública de Promoción y Protección de los Derechos Civiles, Políticos, Económicos, Sociales, Culturales; 3) Diseño y ejecución de políticas a favor de los grupos de especial protección (Personas adultas mayores, Población afroperuana, Personas con discapacidad, Mujeres, Niños, niñas y adolescentes, Personas privadas de libertad, Personas con VIH/SIDA y personas con TBC, trabajadoras y trabajadores del hogar, Personas LGBTI, Defensores y defensoras de derechos humanos, Pueblos indígenas, Personas en situación de movilidad -MIGRANTES- y Personas víctimas de la violencia ocurrida entre los años 1980 y 2000); 4) Fortalecimiento del Ordenamiento Jurídico Interno a través de la Implementación de Instrumentos Internacionales, para la Promoción y Protección de los Derechos Humanos; y 5) Implementación de Estándares Internacionales sobre Empresas y Derechos Humanos.

En suma, tomando en consideración lo establecido en la Política Nacional Migratoria y los Enfoques, Principios y Lineamientos que deben sustentar la Política Sectorial Migratoria Interna, podemos afirmar que ambas políticas (Nacional y Sectorial, respectivamente), recogen el Enfoque de Derechos Humanos, el mismo que se encuentra en la base de la gestión migratoria integral del Estado peruano, sobre todo para el caso de la protección de los 
Grupos Vulnerables (NNA migrantes, específicamente) y es de obligatorio cumplimiento para todas las entidades del Estado en todos los niveles de gobierno, acorde con el ámbito de sus competencias y funciones.

A continuación, repasaremos algunos apuntes doctrinarios, normativos y jurisprudenciales (y otras decisiones) a nivel del Orden Jurídico Interno y el Derecho Internacional, los mismos que han permitido recoger el Enfoque de Derechos Humanos y la Protección de los Grupos Vulnerables (NNA migrantes, específicamente) en la Política Migratoria del Estado peruano.

\subsection{Apuntes Doctrinarios sobre la incorporación del Enfoque de Derechos Humanos y la Protección de los Grupos Vulnerables en la Política Migratoria y el Ordenamiento Jurídico del Estado peruano}

Previamente, es importante señalar que cuando se trata de garantizar los derechos humanos de los ciudadanos, en especial, si estamos frente a personas que forman parte de los denominados Grupos Vulnerables, como es el caso de: a) Víctimas de violencia familiar y sexual;b) Víctimas de trata de personas y tráfico ilícito de migrantes; c) Situación migratoria irregular; d) Sustracción internacional de niñas, niños y adolescentes; e) Personas privadas de la libertad; f) Personas con discapacidad; g) Niñas, niños y adolescentes; h) Personas con grave enfermedad; i) Adultos mayores; j) Personas pertenecientes a pueblos indígenas y tribales; k) Personas en situación de pobreza y extrema pobreza; 1) Desplazados forzados; $\mathrm{m}$ ) Personas que sufren discriminación; n) Niñas, niños y adolescentes no acompañados; o) Mujeres embarazadas; p) Población LGTBI; y q) Otros que requieren protección en atención a una afectación o grave amenaza a sus derechos fundamentales, necesariamente tendremos que hacer alusión a la denominada "protección multinivel de los derechos humanos" (internacional, constitucional, legal, e infralegal).

A propósito de ello, corresponde advertir que la protección multinivel de los derechos humanos, a nivel nacional e internacional, no es ni ha sido un proceso ascendente y triunfal, pero ha podido asentarse en función de los desarrollos internacionales y regionales con la democratización de la sociedad y del Estado. Sobre esta base, dirá Cesar Landa Arroyo, se inició el fenómeno de la internacionalización del Derecho Constitucional, así como el proceso de constitucionalización del Derecho Internacional de los Derechos Humanos.

Así, el curso histórico del Estado peruano desde finales de los gobiernos militares ha ido abriéndose lentamente a la jurisprudencia y doctrina 
internacional de los derechos humanos. Es cierto que no siempre se ha asumido de forma uniforme el carácter vinculante de los estándares internacionales en materia de derechos humanos, pero se ha abierto un diálogo jurisdiccional entre la Corte Interamericana de Derechos Humanos (en adelante, Corte IDH) y el Tribunal Constitucional. De allí la necesidad de hacer referencia a lo que tanto la Corte IDH como el Tribunal Constitucional han señalado sobre los Derechos y Garantías de los Migrantes, en especial de los menores de edad.

Ahora bien, tomando en consideración -como ya lo hemos señalado- que el Estado peruano ha suscrito los principales instrumentos universales y regionales sobre derechos humanos, especialmente, la Convención Internacional para la Protección de los Derechos de todos los Trabajadores Migrantes y sus Familias, incorporados al ordenamiento jurídico nacional, de conformidad con el artículo $55^{\circ}$ de la Constitución; y que la Cuarta Disposición Final y Transitoria de la Carta Política señala que los tratados ratificados y vigentes sobre derechos humanos forman parte del derecho nacional y se constituyen en parámetro de interpretación obligatoria de los derechos y libertades constitucionalmente reconocidos.

Es por ello, que el Perú viene desplegando su Política Nacional Migratoria en el marco de un certero respeto y cumplimiento de estos tratados, habiendo incorporado progresivamente en el proceso elaboración y coordinación de las políticas públicas el Enfoque de Derechos humanos.

Por lo antes expuesto, conviene precisar que en este punto desarrollaremos tres (3) ejes temáticos:

\section{a. Relaciones entre el Derecho Internacional y el Derecho interno}

El cumplimiento efectivo de las disposiciones del derecho internacional, según Elizabeth Salmón Gárate (Curso de Derecho Internacional Público: 2014), sigue fuertemente vinculado a la actuación estatal y, más concretamente, al Estado y su marco jurídico nacional. De acuerdo con la teoría del desdoblamiento funcional de Scelle, los Estados son creadores y destinatarios del derecho internacional, por lo que, al no existir en el ordenamiento internacional órganos centralizados y superiores a los Estados que controlen de manera general la aplicación de sus normas, queda a estos ser los principales gestores de la aplicación del derecho internacional.

Entonces, según esta misma autora, lo que se plantea, es que el cumplimiento de las normas internacionales requiere la puesta en 
práctica de medidas nacionales de distinta naturaleza destinadas a que las normas internacionales tengan plena vigencia en el derecho interno. Dicho, en otros términos, que permitan que el ordenamiento nacional resulte conforme con los compromisos internacionales asumidos por los Estados (la protección de los derechos de los Grupos Vulnerables, los NNA migrantes, por ejemplo), es decir, un proceso de implementación que deviene en una obligación imperiosa del derecho internacional.

Consecuencia evidente es que, por ejemplo, los tratados de derechos humanos han consagrado expresamente la obligación positiva de respetar y garantizar, que busca la derogación, adopción y no adopción de normas nacionales contrarias a las obligaciones internacionales.

Así, por ejemplo, el artículo 2.1 del Pacto Internacional de Derechos Civiles y Políticos y el artículo 1.1 de la Convención Americana de Derechos Humanos. En el caso particular del Sistema Interamericano, la Corte IDH, en el Caso Velásquez Rodríguez vs. Honduras, ha señalado que el contenido del deber de garantía incluye cuatro obligaciones: prevención, investigación, sanción y reparación.

La implementación, por tanto, se convierte en una herramienta necesaria para la vigencia de normas del derecho internacional. Esta consiste en el conjunto de actos realizados para que el Estado esté en condiciones de cumplir con la norma internacional a la que se hubiere obligado $y$, en consecuencia, es condición para su aplicación. A tal efecto, se deberá tener en cuenta la naturaleza autoejecutiva o no autoejecutiva de las normas internacionales $\mathrm{y}$, desde el ámbito del derecho interno, aquellas normas predispuestas en abstracto para la recepción y jerarquía de las normas internacionales $\mathrm{y}$, en su caso, aquellas que se adoptan en concreto para la efectiva aplicación de la norma internacional.

En tal sentido, debemos partir de la siguiente premisa, refiere Salmón Gárate: el derecho internacional no prescribe una técnica determinada de introducción de las normas internacionales en los ordenamientos estatales, siendo, en consecuencia, la libertad de medios la regla. Esto lleva, según Landa Arroyo ("La Convencionalización del Derecho Peruano": 2016), a que cada Estado pueda decidir unilateralmente la forma en que el derecho internacional se aplicará al Estado y sus individuos (mecanismos 
de recepción del derecho internacional) y el rango que detentarán las normas internacionales (jerarquía).

Dicho esto, se puede advertir que son dos los temas que resultan de especial relevancia en el marco de la interacción entre el derecho interno y el derecho internacional: i) La incorporación de las normas internacionales en el ordenamiento interno; y ii) La jerarquía que los Estados asignan, a estas en el marco del derecho interno.

\section{b. La incorporación de las normas internacionales en el ordenamiento interno}

La Constitución ha optado por un modelo monista. En efecto, refiere Landa Arroyo, el artículo 55 señala que "los tratados celebrados por el Estado y en vigor forman parte del derecho nacional.

La concepción monista plantea la unidad del sistema internacional y de los órdenes jurídicos estatales. Para Kelsen, verdadero propulsor de esta teoría, la "norma fundamental" del sistema podía ser el ordenamiento estatal (monismo con primacía del derecho interno) o el internacional (monismo con primacía del derecho internacional), inclinándose, desde 1934, hacia la superioridad del derecho internacional, según lo afirma Pastor Ridruejo. De esto surge que la norma internacional se integra en el sistema estatal sin necesidad de ningún acto expreso de voluntad del Estado ("transformación"). Cualquier conflicto entre normas provenientes del orden internacional y el interno se tendría que solucionar en términos de jerarquía normativa, aunque las formas radicales de monismo sostuvieron que lo que procedía era la nulidad de la norma interna.

El monismo kelseniano constituyó, en palabras de Antonio Cassese, una construcción teórica admirable, que encontró sustento en el internacionalismo y pacifismo. Pero que, además, tuvo un impacto ideológico significante y puso énfasis en el papel del derecho internacional como factor de control de la conducta estatal y sirvió para consolidar la noción de que los agentes del Estado debían obedecer los estándares internacionales y poner los imperativos internacionales antes que las demandas nacionales.

Ahorabien, deacuerdocon lodispuestoenel artículo $55^{\circ}$ constitucional mencionado, los tratados internacionales se incorporan de modo directo al ordenamiento nacional. Sobre esta cualidad automática y normativa, el Tribunal Constitucional ha señalado que, por ejemplo, 
para el caso de los Tratados de Derechos Humanos ratificados por el Perú "por pertenecer al ordenamiento jurídico interno, son derecho válido, eficaz y, en consecuencia, inmediatamente aplicable al interior del Estado. Así lo manifestó el Tribunal Constitucional en la STC N 5854-2005-PA/TC (Caso Pedro Andrés Lizana Puelles contra el Jurado Nacional de Elecciones).

En el caso peruano, los artículos $56^{\circ}$ y $57^{\circ}$ constitucionales, regulan la aprobación de los tratados mediante un sistema de incremento de requisitos que depende de las materias que dicho tratado pretende normar:

- Tratados que requieren aprobación congresal (artículo 56 ${ }^{\circ}$. Los tratados que versen sobre las siguientes materias requieren aprobación del Congreso antes de su ratificación: derechos humanos; soberanía, dominio o integridad territorial; defensa nacional; obligaciones financieras del Estado; los tratados que crean modifican o suprimen tributos; los que exigen modificación o derogación de alguna ley, y los que requieren de medidas legislativas para su ejecución.

- Tratados que no requieren aprobación congresal (artículo 57). Sobre el resto de materias el presidente celebra y ratifica los tratados dando cuenta al Congreso.

Asimismo, este artículo, dispone, en su segundo párrafo que los tratados que afectan disposiciones constitucionales deben ser aprobados mediante el procedimiento que rija la reforma constitucional dispuesta en el artículo $206^{\circ}$ de la Constitución, a fin de evitar la contradicción normativa. Pese a que este párrafo se encuentra contenido en el artículo $57^{\circ}$ constitucional, que se inicia con el tema de los "Tratados Ejecutivos", no debe generar confusión, con que solo se aplique a este tipo específico de normas internacionales.

Al respecto, Salmón Gárate nos recuerda que el Tribunal Constitucional, si bien no se ha pronunciado directamente sobre esta materia, al analizar su aplicación, lo ha relacionado con los tratados de derechos humanos, que son materia regulada exclusivamente por el artículo $56^{\circ}$ constitucional y que requieren de aprobación congresal. Así lo expuso el Tribunal Constitucional en la STC Nº025-2005-PI/ TC y 0026-2005-PI/TC en los casos Colegio de Abogados de Arequipa y Colegio de abogados del Cono Norte, respectivamente, contra la 
Ley Orgánica del Consejo Nacional de la Magistratura.

\section{c. La jerarquía que los Estados asignan, a las normas internacionales en el marco del derecho interno}

Nuevamente, el derecho internacional no tiene injerencia en la regulación de la jerarquía de sus normas dentro del ordenamiento interno. No obstante, postula el principio de primacía por el que las obligaciones asumidas por el Estado, en virtud de una norma internacional priman sobre las que establece su derecho interno. Esto último, afirma Salmón Gárate, a efectos de la jurisprudencia internacional comprende tanto la Constitución como cualquier otra norma de rango inferior del orden jurídico estatal.

Ahora bien, es importante subrayar que el derecho internacional no postula su primacía en la esfera del derecho interno de los Estados, pues en él se está a lo que el propio Estado disponga por el principio de soberanía. De esta forma, el Estado puede decidir cómo se incorpora el derecho internacional en su ordenamiento jurídico y el rango jerárquico que este tendrá en su relación con otras normas internas. El juez nacional deberá aplicar las disposiciones de su ordenamiento interno, pero si estas le mandan preferir una norma interna en desmedro de una internacional, entonces la aplicación de la norma interna entrañará la responsabilidad del Estado en el plano internacional. Sin embargo, la ley interna o la decisión judicial sigue siendo válida en el sistema nacional.

En suma, el principio de primacía del derecho internacional sobre el derecho interno se manifiesta en que la resolución de cualquier controversia internacional tendrá como criterio que ninguna disposición de derecho interno justifica el incumplimiento de una norma internacional (faceta negativa) y que esta debe ser adecuadamente implementada por los Estados para poder proceder a su cumplimiento (justamente lo que el Estado peruano ha buscado al incorporar el Enfoque de Derechos Humanos y la protección de los Grupos Vulnerables (NNA migrantes, específicamente) en su Política Migratoria.

No obstante, lo antes señalado, es importante referirnos a las soluciones jerárquicas adoptadas por los Estados. En otras palabras, dejaremos constancia acerca de los cuatro escenarios que los Estados soberanos han previsto para regular el rango de las normas internacionales, para luego, hacer especial énfasis en el caso peruano: 
- Que el derecho internacional (o al menos algunas de sus normas) ostente rango supraconstitucional.

- Que el derecho internacional (o al menos algunas de sus normas) ostente rango constitucional.

- Que el derecho internacional (o al menos algunas de sus normas) ostente rango supralegal.

- Que el derecho internacional (o al menos algunas de sus normas) ostente rango legal.

De hecho, afirma Salmón Gárate, estas soluciones constitucionales que han adoptado los Estados no son excluyentes. Es decir, podría ser que un tipo de normas del derecho internacional se le haya asignado un rango y a otro tipo de norma uno superior o inferior. En efecto, es ese el caso peruano. La Constitución, señala Salmón Gárate ("Introducción al Sistema Interamericano de Derechos Humanos": 2019), resulta escueta en cuanto a la jerarquía normativa, en términos generales, y mucho más con relación a la jerarquía del derecho internacional.

Así pues, el único dato normativo que abre una pista es el artículo $200^{\circ}$, numeral 4, de la Constitución que establece que los procesos de inconstitucionalidad proceden contra normas con rango legal: leyes, decretos legislativos, decretos de urgencia, tratados, reglamentos del Congreso, normas regionales de carácter general y ordenanzas municipales. Esto quiere decir que con la promulgación de la Constitución vigente los tratados en general obtuvieron rango legal.

Al respecto, conviene recordar, como lo hace Salmón Gárate, que esta opción del constituyente modificó la regulación introducida por la Constitución de 1979, que contenía dos normas que nos permitían establecer el rango de los tratados: el artículo $10^{\circ}$, que estipulaba que "en caso de conflicto entre el tratado y la ley, prevalece el primero", y el artículo $105^{\circ}$, que señalaba que los "preceptos contenidos en los tratados relativos a derechos humanos, tienen jerarquía constitucional".

Es decir que el artículo $10^{\circ}$ asignaba rango supralegal a los tratados en general y el artículo $105^{\circ}$ otorgaba jerarquía superior, de tipo constitucional, a los tratados de derechos humanos. Eso quiere decir que, con la aparición forzosa de la Constitución vigente, se 
produjo una modificación sustancial: se retiró formalmente el rango constitucional a los tratados de derechos humanos y se estableció -de manera general- el rango legal para los tratados.

Sin embargo, refiere Salmón Gárate, esta situación fue subsanada por el Tribunal Constitucional en 2006 cuando emitió la STC 000472004-AI, en la que establecía la pirámide jurídica nacional sobre la base de dos criterios: las categorías y los grados. En estos términos, el Tribunal Constitucional retomó el criterio de la Constitución de 1979 y diferenció los tratados de derechos humanos del resto de tratados y les asignó rango constitucional, sin perjuicio del rango legal ya deducido para el resto de tratados.

Ahora bien, ¿cuál es el fundamento para la asignación del rango constitucional de los tratados de derechos humanos?

Sobre el particular, se han ensayado dos aproximaciones. Primero, podría recurrirse a la IV Disposición Final y Transitoria, que establece que "las normas relativas a los derechos y a las libertades que la Constitución reconoce se interpretan de conformidad con la Declaración Universal de Derechos Humanos y con los tratados y acuerdos internacionales sobre las mismas materias ratificados por el Perú". Sin embargo, esta disposición sólo establece un criterio hermeneútico, pero no está destinada a otorgar un rango diferenciado a los mismos.

Segundo, el Tribunal Constitucional ha mantenido una línea jurisprudencial constante que lo ha llevado a concluir, como bien lo apunta Salmón Gárate, que el fundamento constitucional de los tratados de derechos humanos proviene de la "cláusula abierta de derechos", consignada en el artículo $3^{\circ}$ de la Constitución de 1993, que señala que "la enumeración de los derechos (en el artículo $2^{\circ}$ ) no excluye los demás que la Constitución garantiza, ni otros de naturaleza análoga o que se fundan en la dignidad del hombre, o en los principios de soberanía del pueblo, del Estado democrático de derecho y de la forma republicana de gobierno".

En efecto, el Tribunal Constitucional señaló en la STC 0025-2005PI/TC y 0026-2005-PI/TC, respectivamente, que "si en las fuentes de nuestro ordenamiento jurídico se indaga por aquella donde se pueda identificar derechos que ostenten "naturaleza análoga" a los derechos que la Constitución enuncia en su texto, resulta indudable que tal fuente reside, por antonomasia, en los tratados 
internacionales sobre derechos humanos que conforman nuestro ordenamiento jurídico. En consecuencia, dichos tratados, todos ellos de consumo, enuncian derechos de naturaleza constitucional.

Con lo cual, puede afirmarse, como también lo ha hecho Landa Arroyo, que los temas relativos al rango de los tratados han sido jurisprudencialmente completados por el Tribunal Constitucional. En suma, los tratados, en términos generales, tienen rango legal y solo los tratados de derechos humanos ostentan rango constitucional.

Por tanto, tomando en consideración lo establecido por la Doctrina del Derecho Constitucional y el Derecho Internacional Público (Derecho Internacional de los Derechos Humanos, especialmente), respectivamente, queda claro que el Estado peruano debe diseñar su Política Migratoria -y así lo viene haciendo desde el 2017, sobre todo- recogiendo el Enfoque de Derechos Humanos y la protección de los Grupos Vulnerables (NNA migrantes, específicamente) en la misma, siendo de obligatorio cumplimiento para todas las entidades del Estado en todos los niveles de gobierno, acorde con el ámbito de sus competencias y funciones.

En suma, son estos apuntes doctrinarios los que en su momento han servido de fundamento para que el Poder Ejecutivo, a través de sus instituciones, diseñe políticas públicas que recogen el Enfoque de Derechos Humanos y la Protección de los Grupos Vulnerables en la Política Migratoria del Estado Peruano.

2.3 Apuntes Normativos sobre la incorporación del Enfoque de Derechos Humanos y la Protección de los Grupos Vulnerables en la Políica Migratoria y el Ordenamiento Jurídico del Estado peruano

Al respecto, tomando en consideración que en la Política Nacional Migratoria se ha señalado expresamente que la Constitución establece las directrices en materia de política migratoria que parten del reconocimiento de "la defensa de la persona humana y el respeto de su dignidad como el fin supremo de la sociedad y del Estado", corresponde repasar las disposiciones que son el sustento normativo que hace posible la incorporación del Enfoque de Derechos Humanos y la protección de los Grupos Vulnerables (NNA, específicamente) en la Política Migratoria del Estado peruano.

En atención a lo expuesto previamente, conviene precisar, tomando en consideración lo relacionado a la "protección multinivel de los derechos humanos", que en este punto haremos referencia a las disposiciones 
constitucionales, legales e infralegales relacionadas con el asunto de la referencia.

a. Disposiciones constitucionales que hacen posible la incorporación del Enfoque de Derechos Humanos y la Protección de los Grupos Vulnerables (NNA, específicamente) en la Política Migratoria del Estado peruano

Sobre el particular, consideramos oportuno reproducir el tenor de diversos artículos constitucionales que hacen posible la incorporación del Enfoque de Derechos Humanos y la protección de los Grupos Vulnerables (NNA, específicamente), para la adecuada implementación de los respectivos instrumentos internacionales de derechos humanos, como parte de las responsabilidades internacionales asumidas por nuestro país, en consonancia con lo expuesto en la Política Migratoria del Estado peruano:

o ¿Cuál es el fin supremo de la sociedad y del Estado?

El artículo $1^{\circ}$ de la Constitución establece que la defensa de la persona humana y el respeto de su dignidad son el fin supremo de la sociedad y del Estado.

o ¿Cuáles son los deberes primordiales del Estado?

El artículo $44^{\circ}$ de la Constitución establece que son deberes primordiales del Estado: defender la soberanía nacional; garantizar la plena vigencia de los derechos humanos; proteger a la población de las amenazas contra su seguridad; y promover el bienestar general que se fundamenta en la justicia y en el desarrollo integral y equilibrado de la Nación.

Asimismo, en el referido artículo, se señala que es deber del Estado establecer y ejecutar la política de fronteras y promover la integración, particularmente latinoamericana, así como el desarrollo y la cohesión de las zonas fronterizas, en concordancia con la política exterior.

o ¿Cuál es la protección que la Constitución le confiere a los menores de edad?

El artículo $4^{\circ}$ de la Constitución establece que la comunidad y el Estado protegen especialmente al niño, al adolescente, a la madre 
y al anciano en situación de abandono.

o ¿Cuál es la protección que la Constitución le confiere al derecho a la libertad de tránsito?

El artículo $2^{\circ}$, numeral 11 de la Constitución establece que toda persona (incluyendo a los menores) tiene derecho a elegir su lugar de residencia, a transitar por el territorio nacional y a salir de él y entrar en él, salvo limitaciones por razones de sanidad o por mandato judicial o por aplicación de la Ley de Extranjería.

o ¿Cómo se regulan los tratados en la Constitución?

El artículo $55^{\circ}$ de la Constitución establece que los tratados celebrados por el Estado y en vigor forman parte del derecho nacional.

o ¿Cómo se regula la interpretación de los derechos fundamentales en la Constitución?

La Cuarta Disposición Final y Transitoria establece que las normas relativas a los derechos y a las libertades que la Constitución reconoce se interpretan de conformidad con la Declaración Universal de Derechos Humanos y con los tratados y acuerdos internacionales sobre las mismas materias ratificados por el Perú.

o ¿Cuál es la posición jurídica de la Constitución y las leyes en el ordenamiento jurídico peruano?

El artículo $51^{\circ}$ de la Constitución establece que la Constitución prevalece sobre toda norma legal; la ley, sobre las normas de inferior jerarquía, y así sucesivamente.

o ¿Dónde encontramos los principios de protección especial e interés superior del niño en el marco normativo supranacional?

Los principios de protección especial e interés superior del niño, se encuentran reconocidos en el Principio 2 de la Declaración de los Derechos del Niño, el artículo 25.2 de la Declaración Universal de Derechos Humanos, el artículo 3.1 de la Convención sobre los Derechos del Niño, el artículo $19^{\circ}$ de la Convención Americana sobre Derechos Humanos, los artículos 23.4 y 24.1 del Pacto Internacional de Derechos Civiles y Políticos, el artículo 10.3 del 
Pacto Internacional de Derechos Económicos, Sociales y Culturales, el artículo $16^{\circ}$ del Protocolo de San Salvador.

En suma, son estas disposiciones constitucionales las que en su momento han servido de fundamento para que el Poder Ejecutivo, a través de sus instituciones, diseñe políticas públicas que recojan el Enfoque de Derechos Humanos y la Protección de los Grupos Vulnerables en la Política Migratoria del Estado Peruano.

b. Disposiciones legales que hacen posible la incorporación del Enfoque de Derechos Humanos y la Protección de los Grupos Vulnerables (NNA, específicamente) en la Política Migratoria del Estado peruano

Al respecto, consideramos oportuno reproducir el tenor de diversos artículos de normas con rango legal que hacen posible la incorporación del Enfoque de Derechos Humanos y la Protección de los Grupos Vulnerables, para la adecuada implementación de los respectivos instrumentos internacionales de derechos humanos, como parte de las responsabilidades internacionales asumidas por nuestro país, en consonancia con lo expuesto en la Política Migratoria del Estado peruano:

o ¿Qué estipula la Ley Orgánica del Poder Ejecutivo, Ley 29158?

Primero, el artículo I del Título Preliminar (Principio de Legalidad), señala que las autoridades, funcionarios y servidores del Poder Ejecutivo (como MIGRACIONES) están sometidos a la Constitución Política del Perú a las leyes y a las demás normas del ordenamiento jurídico. Desarrollan sus funciones dentro de las facultades que les estén conferidas.

Segundo, el artículo II del Título Preliminar (Principio de Servicio al Ciudadano) establece que las entidades del Poder Ejecutivo están al servicio de las personas y de la sociedad (sobre todo de los Grupos Vulnerables como los migrantes irregulares, desplazados, menores de edad, entre otros), actúan en función de sus necesidades, así como del interés general de la nación.

Asimismo, dispone que la gestión en las entidades del Poder Ejecutivo debe eliminar todo requisito y procedimiento innecesario, pues los procesos deben ser racionales a los fines que se persigue cumplir; y que la misma debe servir para enfrentar los riesgos que afecten la vida de las personas (sobre todo de los 
Grupos Vulnerables como los migrantes irregulares, desplazados, menores de edad, entre otros), y para asegurar la prestación de los servicios fundamentales.

Tercero, el artículo III del Título Preliminar (Principio de Inclusión y Equidad), dispone que la gestión de las entidades del Poder Ejecutivo promueve la incorporación económica, social, política y cultural de los grupos sociales, excluidos y vulnerables (Grupos Vulnerables como los migrantes irregulares, desplazados, menores de edad, entre otros), y de las personas con discapacidad de cualquier tipo que limita su desempeño y participación activa en la sociedad.

Cuarto, el artículo $4^{\circ}$ (Competencias exclusivas del Poder Ejecutivo), establece que una de las competencias exclusivas del Poder Ejecutivo es la de diseñar y supervisar políticas nacionales y sectoriales, las cuales son de cumplimiento obligatorio por todas las entidades del Estado en todos los niveles de gobierno.

Por último, el artículo $6^{\circ}$ (Funciones del Poder Ejecutivo), establece que una de las funciones del Poder Ejecutivo es la de planificar, normar, dirigir, ejecutar y evaluar las políticas nacionales y sectoriales en conformidad con las políticas de Estado.

o ¿Qué estipula la Ley $\mathrm{N}^{\circ} 1266$, Ley Orgánica del Ministerio del Interior?

El artículo $5^{\circ}$ (Funciones Específicas), establece que son funciones específicas del Ministerio del Interior formular, dirigir, coordinar y evaluar las políticas de seguridad ciudadana en atención a la prevención del delito, seguridad privada, control y fiscalización, así como, el registro y los servicios migratorios.

Asimismo, estipula que el Ministerio del Interior tiene por función supervisar y evaluar el cumplimiento de las políticas en materia migratoria interna.

o ¿Qué estipula el Decreto Legislativo N 1130, Ley de creación de MIGRACIONES?

Primero, el artículo $1^{\circ}$ establece que MIGRACIONES es un Organismo Técnico Especializado adscrito al Ministerio del Interior con personería jurídica de derecho público interno, con autonomía administrativa, funcional y económica en el ejercicio 
$\underline{\text { de sus atribuciones. }}$

Segundo, el artículo 2 dispone que tiene competencia en materia de política migratoria interna y participa en la política de seguridad interna y fronteriza. Coordina el control migratorio con las diversas entidades del Estado que tengan presencia en los Puestos de Control Migratorio o Fronterizo del país para su adecuado funcionamiento. Tiene competencia de alcance nacional.

Tercero, el artículo $6^{\circ}$ señala que MIGRACIONES tiene, entre otras, las siguientes funciones:

a) Proponer la política sectorial en el ámbito de su competencia.

b) Ejecutar la política migratoria interna, en el marco de su competencia y de conformidad con la normatividad y los tratados internacionales, promoviendo la integración de las personas migrantes a la sociedad peruana.

c) Autorizar, denegar y controlar el ingreso, salida y permanencia legal de los extranjeros al país.

d) Impedir el ingreso o la salida a nacionales y extranjeros que no cumplan con los requisitos, establecidos por la normativa vigente.

e) Participar en la política de Seguridad Nacional vinculada al Control Migratorio o Fronterizo del tránsito de personas.

f) Desarrollar las acciones de seguridad y control migratorio en zonas de Frontera y en todo el territorio nacional, en el marco de sus competencias.

g) Autorizar y registrar el movimiento migratorio de las personas en los Centros Binacionales de Atención Fronteriza (CEBAF).

h) Participar en las acciones conjuntas de control con las diversas entidades del Estado que tengan presencia en los puestos de control migratorio o fronterizo.

i) Participar en la política de Seguridad Nacional vinculada al Control Migratorio o Fronterizo del tránsito de personas.

j) Desarrollar las acciones de seguridad y control migratorio en zonas de Frontera y en todo el territorio nacional, en el marco de sus competencias.

k) Autorizar y registrar el movimiento migratorio de las personas en los Centros Binacionales de Atención Fronteriza (CEBAF).

1) Autorizar excepcionalmente la realización del control migratorio en lugar distinto al Puesto de Control Migratorio o Fronterizo, así como inspeccionar los medios de transporte nacional e internacional, en el territorio nacional y en coordinación con 
las autoridades competentes, con el fin de aplicar la normativa migratoria vigente.

m) Participar en las acciones conjuntas de control con las diversas entidades del Estado que tengan presencia en los puestos de control migratorio o fronterizo.

\section{o ¿Qué estipula el Decreto Legislativo $N^{\circ} 1350$, Ley de Migraciones?}

Previamente, es importante señalar que el literal f) del numeral 2) del artículo $2^{\circ}$ de la Ley 30506, autorizó al Poder Ejecutivo a legislar en materia de seguridad ciudadana a fin de dictar normas para mejorar la política migratoria interna y externa, la Superintendencia Nacional de Migraciones, así como la regulación de seguridad fronteriza, respetando los derechos de las niñas, niños y adolescentes y sin que ello implique la expulsión de uno o los dos progenitores por infracciones de carácter administrativo.

Así, por ejemplo, cuando se señala que el Estado peruano debe facilitar la reunión de los trabajadores migratorios con sus cónyuges o con aquellas personas que mantengan con el trabajador migratorio una relación de efectos equivalentes al matrimonio, al igual que con sus hijos sin distinción alguna con base en el género.

\section{o El Título Preliminar}

Primero, el artículo I del Título Preliminar (Principio de respeto a los derechos fundamentales) señala que, en atención al respeto de la dignidad de toda persona humana conforme a la Constitución Política del Perú, el Estado garantiza al extranjero el respeto por sus derechos fundamentales conforme a lo previsto en el marco normativo vigente.

Segundo, el artículo II del Título Preliminar (Principio de soberanía) establece que el Estado ejerce soberanía sobre la integridad de su territorio y sobre los nacionales y extranjeros que en él se encuentren.

Tercero, el artículo III del Título Preliminar (Principio de reconocimiento del aporte de los migrantes en el desarrollo del país y del principio de libre tránsito), dispone que el Estado promueve una migración segura y defiende la libertad de tránsito internacional. 
Cuarto, el artículo IV del Título Preliminar (Principio de integración del migrante) estipula que el Estado promueve la integración del extranjero y su familia a la sociedad y cultura peruana.

Quinto, el artículo V del Título Preliminar (Principio de unidad migratoria familiar) señala que el Estado garantiza y vela por la unidad familiar de los extranjeros y nacionales.

Sexto, el artículo VI del Título Preliminar (Principio de interés superior del niño y adolescente), establece que en toda medida concerniente al niño y adolescente que adopte el Estado a través de todas sus instituciones, así como en la acción de la sociedad, se considerará el principio del interés superior del niño y adolescente y el respeto a sus derechos.

Sétimo, el artículo VII del Título Preliminar (Principio de no criminalización de la migración irregular), dispone que el Estado formula y ejecuta su política migratoria bajo el principio de no criminalización de la migración irregular.

Octavo, el artículo XII (Principio de formalización migratoria), estipula que el Estado promueve las medidas necesarias para la formalización de los extranjeros que deseen ingresar y permanecer en el territorio nacional. Favorece la regularización migratoria como acción permanente que facilita la protección de la persona humana y prevenga o corrija situaciones de vulneración o afectación a la dignidad humana, así como de sus derechos y libertades.

\section{o Otras disposiciones del mismo cuerpo normativo}

Primero, el artículo $3^{\circ}$ señala expresamente que la finalidad de la norma es contribuir a la integración de los migrantes y garantizar los derechos a todas las personas nacionales y extranjeras en el territorio peruano, conforme al ordenamiento jurídico vigente.

Segundo, el artículo $4^{\circ}$ establece que en el ámbito interno (competencia de MIGRACIONES) la Política Migratoria se orienta a determinar la relación del Estado peruano para efectos del ingreso, permanencia, residencia, y salida del territorio peruano, respecto a las personas nacionales y extranjeras, según corresponda. 
Tercero, el artículo $5^{\circ}$ dispone que MIGRACIONES, en su calidad de organismo técnico especializado adscrito al Ministerio del Interior MININTER, es la autoridad en materia migratoria interna.

Cuarto, el artículo $6^{\circ}$ estipula que MIGRACIONES, de conformidad con los instrumentos internacionales suscritos por el Perú y normativa nacional, establece el conjunto de normas, procedimientos, técnicas e instrumentos que regulan su función migratoria, en el marco de sus competencias.

Quinto, el artículo $9^{\circ}$ señala -sobre los derechos de los extranjerosque el Estado reconoce al extranjero el goce y ejercicio de los derechos fundamentales establecidos en la Constitución, tales como el acceso a la salud, a la educación y trabajo en igualdad de condiciones que los nacionales, salvo las prohibiciones y limitaciones establecidas en la normativa vigente; y que además, el Estado proporciona al extranjero información sobre los requisitos para su ingreso, permanencia, residencia y salida del territorio nacional, y cualquier otra información que sea necesaria.

Sexto, el artículo $11^{\circ}$ establece -sobre las personas en situación de vulnerabilidad- que MIGRACIONES y el Ministerio de Relaciones Exteriores ponen en conocimiento de las autoridades competentes las situaciones de vulnerabilidad en que se encuentren las personas migrantes, para la adopción de las acciones administrativas o jurisdiccionales que correspondan para la protección de sus derechos, en particular las referidas a niños, niñas y adolescentes, adulto mayor, personas con discapacidad, o que pertenecen a un pueblo indígena víctima de trata de personas y tráfico de migrantes, víctimas de violencia familiar y sexual, y quienes requieren protección en atención a una grave amenaza o afectación a sus derechos fundamentales; y que ambas instituciones en el ámbito de sus competencias adoptan los criterios para asistir a las personas en situación de vulnerabilidad; pudiendo emitir los documentos $\mathrm{y} / \mathrm{o}$ permisos de permanencia temporal o residencia pertinentes.

o ¿Qué nos dice la Ley del Procedimiento Administrativo General, Ley $\mathrm{N}^{\circ} 27444$ ?

Primero, el artículo IV del Título Preliminar de la Ley señala que los trámites establecidos por la autoridad administrativa deberán ser sencillos, debiendo eliminarse toda complejidad innecesaria; es 
decir, los requisitos exigidos deberán ser racionales y proporcionales a los fines que se persigue cumplir (Principio de Simplicidad).

Asimismo, el mismo artículo establece que la autoridad administrativa deberá establecer requisitos similares para trámites similares, garantizando que las excepciones a los principios generales no serán convertidas en la regla general. Toda diferenciación deberá basarse en criterios objetivos debidamente sustentados (Principio de Uniformidad).

Segundo, el artículo V del Título Preliminar de la referida Ley dispone que son fuentes del procedimiento administrativo: a) Las disposiciones constitucionales; b) Los tratados y convenios internacionales incorporados al Ordenamiento Jurídico Nacional; c) Las leyes y disposiciones de jerarquía equivalente; d) Los Decretos Supremos; entre otras.

En suma, son estas disposiciones legales las que en su momento han servido para que el Poder Ejecutivo, a través de sus instituciones, diseñe políticas públicas que recogen el Enfoque de Derechos Humanos y la Protección de los Grupos Vulnerables (NNA, específicamente) en la Política Migratoria del Estado Peruano.

c. Disposiciones Infralegales que hacen posible la incorporación del Enfoque de Derechos Humanos y la Protección de los Grupos Vulnerables (NNA, específicamente) en la Política Migratoria del Estado peruano

Al respecto, consideramos oportuno reproducir el tenor de diversos artículos de Disposiciones infralegales que hacen posible la incorporación del Enfoque de Derechos Humanos y la protección de los Grupos Vulnerables (NNA, específicamente), en la Política Migratoria del Estado peruano.

o ¿Qué estipula el Reglamento del Decreto Legislativo $\mathrm{N}^{\circ} 1350$, aprobado mediante Decreto Supremo 007-2017-IN?

Primero, el artículo $4^{\circ}$ del Reglamento señala que se entiende por NIÑA, NIÑO O ADOLESCENTE NO ACOMPAÑADO, la persona que pretende ingresar o salir del territorio nacional solo, sin la compañía de sus padres, o de tutor nombrado, o curador, o personal responsable del medio de transporte internacional. También es niña, niño o adolescente no acompañado quien queda 
sin compañía de sus padres, o tutor nombrado, a su llegada o permanencia en el territorio nacional.

Segundo, el artículo $5^{\circ}$ del Reglamento -sobre aplicación de tratados y convenios internacionales- establece que los tratados y convenios internacionales de los cuales el Perú es parte y que traten sobre materia migratoria tienen efecto directo y primacía de acuerdo a lo establecido en dichas normas.

Tercero, el artículo $72^{\circ}$ del Reglamento -sobre Calidad Migratoria Especial- dispone que se otorga a las personas extranjeras que deseen realizar actividades que no estén descritas en otras calidades migratorias y se justifica en un tratamiento excepcional, subsidiario y residual por parte de las autoridades migratorias.

Cuarto, el artículo $146^{\circ}$ del Reglamento señala -sobre las medidas de protección de niñas, niños y adolescentes extranjeros no acompañados- que MIGRACIONES evaluará y dispondrá el otorgamiento de la calidad migratoria especial para permitir el ingreso de la niña, niño o adolescente no acompañado a territorio peruano y pone a la niña, niño o adolescente a disposición del Ministerio de la Mujer y de Poblaciones Vulnerables hasta que concluyan las gestiones que permitan determinar su permanencia o salida del territorio peruano; y que el referido Ministerio, podrá solicitar el cambio de calidad migratoria si fuera necesario, y realizará las gestiones que permitan mantener la regularidad migratoria de la niña, el niño o adolescente.

Quinto, el artículo $226^{\circ}$ del Reglamento establece -sobre las personas extranjeras en situación de vulnerabilidad- que son consideradas personas en situación de vulnerabilidad aquellas personas extranjeras que se encuentran en situación de desprotección o riesgo de no acceder al ejercicio pleno de sus derechos fundamentales en nuestro país (sobre todo de los Grupos Vulnerables como los migrantes irregulares, desplazados, menores de edad, entre otros).

Sexto, el artículo $227^{\circ}$ del Reglamento -sobre los supuestos de situaciones de vulnerabilidad- prevé los siguientes casos:

a) Víctimas de violencia familiar y sexual;

b) Víctimas de trata de personas y tráfico ilícito de migrantes;

c) Situación migratoria irregular; 
d) Sustracción internacional de niñas, niños y adolescentes

e) Personas privadas de la libertad;

f) Personas con discapacidad;

g) Niñas, niños y adolescentes;

h) Personas con grave enfermedad;

i) Adultos mayores;

j) Personas pertenecientes a pueblos indígenas y tribales;

k) Personas en situación de pobreza y extrema pobreza;

l) Desplazados forzados;

m) Personas que sufren discriminación;

n) Niñas, niños y adolescentes no acompañados;

o) Mujeres embarazadas;

p) Población LGTBI;

q) Otros que requieren protección en atención a una afectación o grave amenaza a sus derechos fundamentales.

Sétimo, el artículo $228^{\circ}$ del Reglamento -sobre la acreditación de la situación de vulnerabilidad- dispone que las autoridades migratorias, cuando corresponda, podrán solicitar a las entidades correspondientes de oficio o a solicitud del administrado, la documentación que acredite la situación de vulnerabilidad; y que MIGRACIONES puede verificar la situación de vulnerabilidad o de ser el caso de su continuidad que amerita la especial protección, pudiendo contar con el apoyo de autoridades competentes.

Octavo, el artículo $229^{\circ}$ del Reglamento -sobre protección de personas extranjeras en situación de vulnerabilidad- estipula que las autoridades migratorias pondrán en conocimiento de las autoridades competentes, Ministerio Público, Poder Judicial, Policía Nacional del Perú, Ministerio de la Mujer y Poblaciones Vulnerables, Ministerio de Salud, Ministerio del Trabajo y Promoción del Empleo y otras entidades según corresponda, la situación de un presunto caso de vulnerabilidad en que se encuentren las personas migrantes para la adopción de las acciones administrativas o jurisdiccionales que correspondan para la protección de sus derechos, en los supuestos establecidos en el artículo $227^{\circ}$ del Reglamento.

Asimismo, en el referido artículo se señala que las entidades públicas coordinarán las acciones de protección y prevención dirigidas a las personas extranjeras que se encuentran en el territorio nacional en situación de vulnerabilidad. Así, las Entidades tienen el deber, en el marco de sus competencias, de tomar acción y dar atención 
oportuna a cada caso en concreto.

Noveno, el artículo $230^{\circ}$ del Reglamento -sobre medidas migratorias de protección- señala que las Autoridades Migratorias expedirán los documentos y/o permiso temporal de permanencia a las personas extranjeras en situación de vulnerabilidad, previo informe técnico de la unidad orgánica especializada en la materia; medidas que incluyen el otorgamiento de ampliaciones de plazo y exoneración de multas y derechos de tramitación estipulados en la normatividad migratoria vigente $u$ otros, que faciliten la atención a las circunstancias especiales de cada caso en concreto.

A su vez, el referido artículo establece que MIGRACIONES, en casos de situación de vulnerabilidad, podrá exonerar de la presentación de requisitos establecidos para los procedimientos estipulados en la normatividad migratoria vigente $u$ otros, previo informe del órgano especializado en la materia; y que MIGRACIONES podrá otorgar la Calidad Migratoria Especial de manera excepcional a personas extranjeras en extrema situación de vulnerabilidad, permitiendo la permanencia en situaciones no contempladas en las demás calidades migratorias, calidad que será otorgada previo informe del órgano especializado en la materia.

En suma, son estas disposiciones infralegales las que en su momento han servido para que el Poder Ejecutivo, a través de sus instituciones, diseñe políticas públicas que recogen el Enfoque de Derechos Humanos y la Protección de los Grupos Vulnerables en la Política Migratoria del Estado Peruano.

2.4 Apuntes Jurisprudenciales y otras decisiones que hacen posible la incorporación del Enfoque de Derechos Humanos y la Protección de los Grupos Vulnerables (NNA, específicamente) en la Política Migratoria y el Ordenamiento Jurídico del Estado peruano

Previamente, tomando como referencia lo expuesto en líneas previas sobre los tratados y convenios internacionales en materia de derechos humanos, como fuentes del Procedimiento Administrativo, resulta oportuno referenciar algunas disposiciones del marco normativo supranacional directamente relacionadas con la Protección de los Derechos Humanos de los Grupos Vulnerables (NNA, específicamente).

\section{- Declaración Universal de Derechos Humanos}


En los artículos $1^{\circ}$ y $2^{\circ}$, respectivamente, se señala que "todos los seres humanos nacen libres e iguales en dignidad y derechos $\mathrm{y}$, dotados como están de razón y conciencia, deben comportarse fraternalmente los unos con los otros" y "toda persona tiene los derechos y libertades proclamados en esta Declaración, sin distinción alguna de raza, color, sexo, idioma, religión, opinión política o de cualquier otra índole, origen nacional o social, posición económica, nacimiento o cualquier otra condición." Dicha Declaración ha sido reconocida por el Estado Peruano (Ratificada por el Perú el 15 de diciembre de 1959).

\section{- Convención Americana de Derechos Humanos}

El artículo 1 establece que "los Estados Partes en esta Convención se comprometen a respetar los derechos y libertades reconocidos en ella y a garantizar su libre y pleno ejercicio a toda persona que esté sujeta a su jurisdicción, sin discriminación alguna por motivos de raza, color, sexo, idioma, religión, opiniones políticas o de cualquier otra índole, origen nacional o social, posición económica, nacimiento o cualquier otra condición social"

Asimismo, en el artículo $19^{\circ}$ se dispone que "todo niño tiene derecho a las medidas de protección que su condición de menor requiere por ser parte de su familia, de la sociedad y del Estado" (Ratificada por el Perú el 27 de julio de 1977). Declaración de los Derechos del Niño

El principio IV y VI, respectivamente, estipulan que "el niño, para el pleno y armonioso desarrollo de su personalidad, necesita amor y comprensión. Siempre que sea posible, deberá crecer al amparo y bajo la responsabilidad de sus padres y, en todo caso, en un ambiente de afecto y de seguridad moral y material; salvo circunstancias excepcionales, no deberá separarse al niño de corta edad de su madre. La sociedad y las autoridades públicas tendrán la obligación de cuidar especialmente a los niños sin familia o que carezcan de medios adecuados de subsistencia. Para el mantenimiento de los hijos de familias numerosas conviene conceder subsidios estatales o de otra índole" (Ratificada por el Perú el 20 de noviembre de 1959).

- Convención Internacional sobre los Derechos del Niño y la Niña

El artículo 18 señala que, a efectos de garantizar y promover los derechos enunciados en dicha Convención, los Estados Partes prestarán la asistencia apropiada a los padres y a los 
representantes legales para el desempeño de sus funciones.

En esa línea, el artículo 20 establece que los niños temporal o permanentemente privados de su medio familiar, o cuyo interés superior exige que no permanezcan en este medio, tendrán derecho a la protección y asistencia especiales del Estado (Ratificada por el Perú en noviembre de 1989).

\section{- La Convencionalización del Derecho Interno}

Ahora bien, la Constitución, en su Cuarta Disposición Final y Transitoria señala que las normas relativas a los derechos y libertades que la Constitución reconoce se interpretan de conformidad con la Declaración Universal de Derechos Humanos y con los tratados y acuerdos internacionales sobre las mismas materias ratificados por el Perú.

Asimismo, el Código Procesal Constitucional, en su artículo V del Título Preliminar establece que el contenido y alcances de los derechos constitucionales deben interpretarse de conformidad con la Declaración Universal de los Derechos Humanos, los tratados sobre derechos humanos, así como de las decisiones adoptadas por los tribunales internacionales sobre derechos humanos constituidos según tratados de los que el Perú es parte.

En ese sentido, la propia Corte Interamericana de Derechos Humanos (en adelante, Corte IDH), en la Opinión Consultiva 21/14, emitida mediante Resolución de fecha 19 de agosto de 2014, ha señalado que, además de sus sentencias, también las Opiniones Consultivas son vinculantes para los Estados que son parte de la Convención Americana de Derechos Humanos, y que, por tanto, los diversos órganos del Estado cuando realicen el correspondiente Control de Convencionalidad, lo hagan también sobre la base de lo que señala la Corte en ejercicio de su competencia no contenciosa o consultiva.

Por lo antes expuesto, consideramos oportuno dar cuenta de lo que la Corte IDH ha señalado sobre la protección de los derechos humanos de los migrantes tanto en el ejercicio de su función Jurisdiccional (Sentencias) como Consultiva (Opiniones Consultivas), pues los criterios expuestos por este Tribunal Interamericano deberían ser la base para que el Poder Ejecutivo, 
a través de sus instituciones, diseñe políticas públicas que recojan el Enfoque de Derechos Humanos y la Protección de los Grupos Vulnerables (NNA, específicamente) en la Política Migratoria del Estado Peruano.

Luego, mencionaremos los fallos emitidos por el Tribunal Constitucional peruano, en los cuales se aborda la problemática migratoria, siguiendo también la línea humanista y tutelar expuesta por la Corte IDH. Por último, haremos alusión a la Observación General 6 "Trato de los menores no acompañados y separados de su familia fuera de su país de origen, elaborada por el Comité de los Derechos del Niño", en su 39० período de sesiones (Del 17 de mayo al 03 de junio de 2005), por tratarse de un pronunciamiento que recoge el Enfoque de Derechos Humanos y la protección de Grupos Vulnerables (NNA, específicamente).

\section{a. La función jurisdiccional de la Corte IDH: Enfoque de Derechos Humanos y Protección de los Grupos Vulnerables}

Al respecto, los casos contenciosos son los siguientes:

\section{Caso Jesús Tranquilino Vélez Loor vs. Panamá (2010)}

En lo contencioso, apunta Salmón Gárate ("Introducción al Sistema Interamericano de Derechos Humanos": 2019), la Corte IDH a través de su fallo recaído en el caso del ciudadano ecuatoriano Jesús Tranquilino Vélez Loor vs. Panamá (2010), identificó las obligaciones de los Estados en relación con sus políticas migratorias y, en particular, se refirió a la incompatibilidad entre el establecimiento de sanciones de carácter punitivo respecto al incumplimiento de las leyes migratorias y las disposiciones de la CADH.

En el mismo libro, la mencionada autora recuerda que la Corte IDH reconoció que los Estados tienen la facultad de controlar y regular el ingreso y permanencia de personas extranjeras en su territorio, pero imponer una medida punitiva al migrante que reingresa al Estado tras una orden de deportación previa no constituye una finalidad legítima de acuerdo con la CADH.

La Corte IDH agregó que la detención de personas por incumplimiento de las leyes migratorias nunca debe ser con fines punitivos, de manera que las medidas privativas de libertad solo deberán ser utilizadas cuando fuere necesario y proporcionado en el caso en concreto, a los fines de asegurar la comparecencia de la persona al proceso 
migratorio o garantizar la aplicación de una orden de deportación, y únicamente durante el menor tiempo posible.

Sin embargo, precisó la Corte IDH, de resultar necesario y proporcionado en el caso específico los migrantes deben ser detenidos en establecimiento específicamente destinados a tal fin, que sean acordes a su situación legal y no en prisiones comunes, cuya finalidad es incompatible con la situación migratoria irregular.

Asimismo, la Corte IDH, volviendo sobre lo ya dicho en su Opinión Consultiva 18/03, afirmó la especial situación de vulnerabilidad en que se encuentran estas personas "pues son los más expuestos a las violaciones potenciales o reales de sus derechos y sufren, a consecuencia de su situación, un nivel elevado de desprotección de sus derechos y diferencias en el acceso a los recursos públicos administrados por el Estado (en relación a los nacionales o residentes). En similar sentido, la Corte IDH, según Salmón Gárate, precisó que los prejuicios culturales acerca de los migrantes permiten la reproducción de las condiciones de vulnerabilidad, lo que dificulta su integración a la sociedad.

Ahora bien, Salmón Gárate, en cuanto al debido proceso, subraya que la Corte IDH indicó que las garantías mínimas establecidas en el artículo 8.2 de la CADH también deben otorgarse a las personas sometidas a procedimientos migratorios administrativos, las cuales se aplican en lo que corresponda.

También, sobre el derecho a la información y acceso efectivo a la asistencia consular, la Corte IDH señaló que, para prevenir detenciones arbitrarias, la persona detenida debe ser notificada de su derecho de establecer contacto con una tercera persona, tal como el funcionario consular, para informarle que se halla bajo custodia del Estado. En esa línea, resaltó el deber estatal de adoptar medidas para garantizar un efectivo e igualitario acceso a la justicia de las personas que se encuentran en una situación de vulnerabilidad agravada, como migrante en situación irregular sometido a una medida de privación de libertad.

Del mismo modo, cabe precisar, en los términos de Salmón Gárate, que ya la Corte IDH había señalado que "las violaciones de derechos humanos cometidas en contra de los migrantes quedan muchas veces en impunidad debido, entre otros, a la existencia de factores culturales que justifican estos hechos, a la falta de acceso a las estructuras de poder en una sociedad determinada, $\mathrm{y}$ a impedimentos normativos 
y fácticos que torna ilusorio un efectivo acceso a la justicia, lo cual plantea un importante problema que pesa sobre los migrantes al momento de buscar acceder a la justicia. En otras palabras: "las políticas de inmigración particularmente restrictivas, junto con las condiciones de vulnerabilidad de los migrantes, pueden conducir a flagrantes violaciones de derechos humanos.

\section{Caso Nadege Dorzema y otros vs. República Dominicana (2012)}

En el referido caso, también citado por Salmón Gárate, la Corte IDH señaló que una violación del derecho a la igualdad y no discriminación se produce también en situaciones y casos de discriminación indirecta reflejada en el impacto desproporcionado de normas, acciones, políticas o en otras medidas, que, aun cuando sean o parezcan ser neutrales en su formulación, o tengan un alcance general y no diferenciado, produzcan efectos negativos para ciertos grupos vulnerables.

En otras palabras, cuando una política general o medida tiene un efecto desproporcionado perjudicial en un grupo particular puede ser considerada discriminatoria aún si no fue dirigida específicamente a ese grupo, en el caso concreto, personas migrantes de nacionalidad haitiana.

\section{Caso de personas dominicanas y haitianas expulsadas vs. República Dominicana (2014)}

En esta jurisprudencia más reciente, la Corte IDH ha recordado el deber de los Estados de prevenir, evitar y reducir la apatridia, y el deber de brindar una protección igualitaria y sin discriminación; precisa, además, que el estatus migratorio de los padres no puede transmitirse a los hijos. De este modo, a propósito del caso referido, la Corte IDH precisó, respecto al primero de los deberes señalados, que los Estados tienen la obligación de no adoptar prácticas o legislación relativas al otorgamiento de la nacionalidad, cuya aplicación favorezca el incremento del número de personas apátridas.

\section{b. La función consultiva de la Corte IDH: Enfoque de Derechos Humanos y Protección de los Grupos Vulnerables}

Al respecto, las Opiniones Consultivas son las siguientes: 


\section{Opinión Consultiva OC 18/03 "Condición Jurídica de los Migrantes Indocumentados"}

Según lo refiere Salmón Gárate, la Corte IDH emitió en 2003 la referida Opinión Consultiva ante una solicitud presentada por México para evaluar la validez de las políticas estatales que permiten un tratamiento diferenciado sobre los migrantes indocumentados. En dicha Opinión Consultiva, la Corte IDH , haciendo suya la definición de la Convención Internacional sobre la Protección de los Trabajadores y de sus Familiares del 18 de diciembre de 1990 de Naciones Unidas, señaló que será considerado como un trabajador migrante indocumentado o en situación irregular aquella persona que no se encuentra autorizada a ingresar, a permanecer y a ejercer una actividad remunerada en el Estado de empleo de conformidad con las leyes de ese Estado y los acuerdos internacionales en que este Estado sea parte.

Así, el principal aporte de esta Opinión Consultiva fue que la Corte IDH, aclaró que los Estados se encuentran sujetos al principio de igualdad y no discriminación -el cual tiene además naturaleza ius cogens- y que, en ese sentido, no pueden establecer políticas públicas, incluidas las de carácter migratorio, que, en su afán de alcanzar objetivos particulares, atenten contra el contenido de este principio.

\section{Opinión Consultiva OC 21/14 “Derechos y Garantías de Niñas y Niños en el contexto de Migración y/o necesidad de Protección Internacional"}

Sobre la protección de los derechos humanos de los menores extranjeros, la Corte IDH ha señalado que, a fin de aplicar la Convención Americana de Derechos Humanos, no es relevante, la razón, causa o motivo por el cual la persona se encuentra en territorio del Estado, a los efectos de la obligación de éste, de respetarle y hacer que se respeten sus derechos humanos. Dicha responsabilidad se agudiza aún más para el caso de niños, niñas y adolescentes, toda vez que, por su sola condición, son considerados una población vulnerable, en atención a la legislación nacional e internacional.

Asimismo, la Corte IDH, sobre la protección de los derechos humanos de los menores extranjeros ha señalado que, a fin de aplicar la Declaración de los Derechos del Niño, que los Estados firmantes no deben impedir el ingreso de niñas y niños extranjeros a territorio nacional, aun cuando se encuentren solos, no deben exigirles 
documentación que no pueden tener y deben dirigirlos de inmediato a personal que pueda evaluar sus necesidades de protección, desde un enfoque en el cual prevalezca su condición de niñas y niños.

Por último, la Corte IDH también ha señalado que los Estados tienen la obligación de priorizar "el enfoque de los derechos humanos desde una perspectiva que tenga en cuenta en forma transversal los derechos de niñas y niños y, en particular, su protección y desarrollo integral, los cuales deben primar por sobre cualquier consideración de la nacionalidad o el estatus migratorio, a fin de asegurar la plena vigencia de sus derechos".

c. El Tribunal Constitucional peruano: Enfoque de Derechos Humanos y Protección de los Grupos Vulnerables

Ahora bien, en el mismo sentido, el Tribunal Constitucional ha señalado que, según la Constitución, todas las personas, por el simple hecho de serlo, tienen derecho a ser iguales ante la ley y a no ser discriminadas o desprotegidas por el Estado. Al respecto, el artículo 2, numeral 2, de la Carta Política, señala que todas las personas -que indudablemente incluye a los migrantes-, son iguales ante la ley y no pueden ser discriminados por motivos de origen, raza, sexo, idioma, religión, opinión, condición económica o de cualquiera otra índole.

Asimismo, sobre el fenómeno migratorio, el Tribunal Constitucional ha señalado que nuestra Constitución "acoge un tratamiento jurídico igualitario en materia de derechos fundamentales entre nacionales y migrantes, con limitaciones excepcionales en el ejercicio de determinados derechos". En ese sentido, se puede concluir que la legislación y jurisprudencia nacionales, respaldan la posición asumida en el ámbito internacional, con debido respeto a los Tratados y Convenios firmados por el Perú (STC Expediente Nº 02744-2015-PA, Fundamento 7).

No obstante, lo antes señalado, sobre el principio superior del niño, niña y adolescente a nivel migratorio, el Tribunal Constitucional ha establecido que "toda actuación administrativa migratoria debe encontrarse acorde con los principios de protección especial e interés superior del niño y adolescente, que, se encuentran regulados a nivel supranacional, constitucional y legal, principios que conforme lo establecido por este Colegiado, prescriben que: "el Estado, a través de sus diferentes órganos, asume el deber positivo de adoptar todas las acciones y medidas legislativas, administrativas, 
sociales y educativas necesarias y eficaces orientadas a proteger a los niños contra cualquier clase de violencia (abuso físico o mental, descuido, trato negligente, malos tratos o explotación) de que sean víctimas, ya sea éste proveniente de autoridades públicas, de sus familiares o de terceros" (STC Expediente $N^{\circ}$ 01817-2019-HC/TC, Fundamento 12).

d. Sobre la Observación General $N^{\circ} 6$ "Trato de los menores no acompañados y separados de su familia fuera de su país de origen", elaborada por el Comité de los Derechos del Niño, en su $39^{\circ}$ período de sesiones (Del 17 de mayo al 03 de junio de 2005)

En esta Observación General Nº 6 (en adelante, OG 6), se han podido distinguir dos casos, vinculados al asunto de la referencia:

Niños separados: Se entiende por niños separados, los menores separados de ambos padres o de sus tutores legales o habituales, pero no necesariamente de otros parientes. Por tanto, puede tratarse de menores acompañados por otros miembros adultos de la familia.

Niños no acompañados: Se entiende por "niños no acompañados" (llamados también "menores no acompañados"), los menores que están separados de ambos padres y otros parientes y no están al cuidado de un adulto al que, por ley o costumbre, incumbe esa responsabilidad.

Ahora bien, con respecto al caso puntual de ambos grupos de niños, en la $\mathrm{OG} \mathrm{N}^{\circ}$ 6, el Comité de los Derechos del Niño hace tres apuntes que nos parece importante subrayar:

Primero, con relación a los menores separados, la Organización de las Naciones Unidas, ha considerado que los niños migrantes que no tienen un tutor o representante legal, o como en los casos mencionados en los antecedentes del informe, cuando el vínculo de representación no pueda certificarse de manera fehaciente, tienen asistido el derecho a que el Estado receptor les designe uno, con la finalidad que puedan ser representados en procedimientos administrativos o judiciales que deban seguir.

Segundo, con relación a los menores separados de su familia, la ONU ha indicado que normalmente se nombrará tutor al familiar adulto que lo acompañe o quien le dispense cuidados sin ser familiar directo, salvo que haya indicios de que ese arreglo no va a 
beneficiar al menor, por ejemplo, cuando éste haya sido maltratado por el adulto acompañante. Cuando un menor esté acompañado por un adulto o una persona que lo cuida sin ser pariente, deberá analizarse con más detenimiento la idoneidad de éste para actuar de tutor. Si el tutor puede atender al menor cotidianamente y está dispuesto a hacerlo, pero no puede representar debidamente el superior interés del menor en todos los campos y ámbitos de su vida, deberán adoptarse medidas complementarias (por ejemplo, el nombramiento de un asesor o representante legal).

Tercero, la ONU, sostiene que en caso un menor no acompañado no cumpla con los requisitos para ser un refugiado en el país receptor, gozará de las medidas complementarias disponibles en la medida determinada por sus necesidades de protección. Entre estas medidas, se cuenta el reconocimiento de todos los derechos humanos que se reconocen a los niños en el territorio perteneciente o sujeto a la jurisdicción del Estado, con inclusión de los derechos que presuponen la estancia legal en dicho territorio.

Entonces, se recomienda que MIGRACIONES, tome en consideración la OG $\mathrm{N}^{\circ} 6$ de la ONU sobre los principios aplicables en relación a los niños separados y niños no acompañados, que indica que el interés superior del niño como consideración primordial en la búsqueda de soluciones a corto y a largo plazo. Es más, resulta necesario tener presente, como lo ha subrayado la ONU, que "en todas las medidas concernientes a los niños que tomen las instituciones públicas o privadas de bienestar social, los tribunales, las autoridades administrativas o los órganos legislativos, una consideración primordial a que se atenderá será el interés superior del niño".

En suma, son estas decisiones jurisdiccionales, consultivas y observaciones generales, emitidas por la Corte IDH, Tribunal Constitucional peruano y Comité de los Derechos Humanos del Niño, respectivamente, las que en su momento han servido para que el Poder Ejecutivo, a través de sus instituciones, diseñen políticas públicas que recogen el Enfoque de Derechos Humanos y la Protección de los Grupos Vulnerables (NNA, específicamente) en la política Migratoria del Estado Peruano.

\subsection{El deber de adecuar el sistema jurídico a los Derechos Humanos}

Siendo que el Estado peruano ha suscrito los principales 
instrumentosuniversalesyregionalessobrederechoshumanos, especialmente, la Convención Internacional para la Protección de los Derechos de todos los Trabajadores Migrantes y sus Familias, incorporados al ordenamiento jurídico nacional, de conformidad con el artículo $55^{\circ}$ de la Constitución; y que la Cuarta Disposición Final y Transitoria de la Carta Política señala que los tratados ratificados y vigentes sobre derechos humanos forman parte del derecho nacional y se constituyen en parámetro de interpretación obligatoria de los derechos y libertades constitucionalmente reconocidos, corresponde reflexionar sobre el deber que asumen los Estados de adecuar el sistema jurídico a los derechos, que se traduce, en este caso, en la incorporación del Enfoque de Derechos Humanos y protección de los Grupos Vulnerables (NNA, específicamente) en la Política Migratoria del Estado peruano.

Al respecto, corresponde señalar que la obligación de que el sistema jurídico tenga coherencia con los derechos, que se llama deber de adecuación, supone lo siguiente: a) Del Sistema Nacional de Protección de Derechos; y b) Del Sistema Internacional de Protección de Derechos.

\section{a) El deber de adecuar en el Sistema Nacional de Protección de Derechos Humanos}

El deber de adecuar las normas y las prácticas a los derechos se encuentra de forma clara y explícita en la Cuarta Disposición Final y Transitoria de la Constitución, cuyo tenor, sobre la interpretación de los derechos fundamentales dice lo siguiente:

"Las normas relativas a los derechos y a las libertades que la Constitución reconoce se interpretan de conformidad con la Declaración Universal de Derechos Humanos y con los tratados y acuerdos internacionales sobre las mismas materias ratificados por el Perú".

Del mismo modo, el artículo V del Título Preliminar del Código Procesal Constitucional, sobre la interpretación de los derechos fundamentales, establece lo siguiente:

"El contenido y alcances de los derechos constitucionales protegidos por los procesos regulados en el presente Código deben interpretarse de conformidad con la Declaración Universal de Derechos Humanos, los tratados sobre derechos humanos, así como de las decisiones adoptadas por los tribunales internacionales sobre derechos humanos constituidos según tratados de los que el Perú es parte". 
Ahora bien, de la lectura de ambos dispositivos normativos (constitucional y legal, respectivamente), se desprende la necesidad de definir lo siguiente: i) Las autoridades obligadas a adecuar; ii) El contenido de la adecuación; iii) Las normas que deben ser adecuadas; iv) Las normas a las que hay que adecuar el sistema jurídico; y v) El límite intangible de la adecuación normativa.

\section{i) Las autoridades obligadas a adecuar}

La Constitución, entre los artículos $90^{\circ}$ a $109^{\circ}$, respectivamente, pone en primer lugar a la Función Legislativa, como obligado primario para adecuar la normativa, porque entre sus funciones primordiales encontramos a las siguientes: “Dar leyes y resoluciones legislativas, así como interpretar, modificar o derogar las existentes, Velar por el respeto de la Constitución y de las leyes, y disponer lo conveniente para hacer efectiva la responsabilidad de los infractores o Aprobar los tratados, de conformidad con la Constitución", según lo estipulado en el artículo $102^{\circ}$ constitucional.

Pero no es la única función ni autoridad con competencia normativa. La Función Ejecutiva también tiene competencia normativa, cuando se le faculta a "Ejercer la potestad de reglamentar las leyes sin transgredirlas ni desnaturalizarlas; y, dentro de tales límites, dictar decretos y resoluciones", según lo estipulado en el artículo $118^{\circ}$, numeral 8 constitucional.

En ese sentido, queda claro que MIGRACIONES, como Organismo Técnico Especializado adscrito al Ministerio del Interior (Poder Ejecutivo), con personería jurídica de derecho público interno, con autonomía administrativa, funcional y económica en el ejercicio de sus atribuciones, según lo establecido en el artículo $1^{\circ}$ del Decreto Legislativo $\mathrm{N}^{\circ} 1130$, puede proponer e impulsar la inmediata y adecuada implementación de los respectivos instrumentos internacionales de derechos humanos, como parte de las responsabilidades internacionales asumidas por el Estado peruano.

\section{ii) El contenido de la adecuación}

La adecuación, según Doctrina y Jurisprudencia Comparada, es formal y material. Landa Arroyo (ver libro "Convencionalización del Derecho Peruano":2016) señala que la adecuación formal tiene que ver con procedimientos establecidos en instrumentos jurídicos, cuando son más favorables o no existen en el sistema jurídico. En lo 
material, se trata de derechos sustantivos, como cuando el instrumento internacional establece un derecho sustantivo no previsto en el derecho interno, así lo ha señalado también la Corte Constitucional del Ecuador, en la Sentencia N 11-18-CN/19.

\section{iii) Las normas que deben ser adecuadas}

Las normas a adecuarse son las leyes y las normas que tienen rango de ley. La palabra ley hace referencia a las normas expedidas por la Función Legislativa. Las otras normas con rango de ley: decretos legislativos, decretos de urgencia, tratados, reglamentos del Congreso, normas regionales de carácter general y ordenanzas municipales.

Cada una de esas normas, según la Constitución, tiene autoridades con sus competencias normativas asignadas y también sus procedimientos. Así, la obligación de adecuar la Constitución corresponde al Poder Legislativo, por ejemplo, reservándole al Poder Ejecutivo la facultad de reglamentar las leyes o, incluso, de presentar Iniciativas Legislativas; y para ello, el Poder Ejecutivo cuenta con el apoyo de un Organismo Técnico Especializado, adscrito al Ministerio del Interior como es el caso de MIGRACIONES.

\section{iv) Las normas a las que hay que adecuar el sistema jurídico}

La lectura de la Cuarta Disposición Final y Transitoria de la Constitución nos permite afirmar que la adecuación es a los derechos. Los derechos se encuentran, en tres fuentes jurídicas que las autoridades, según su competencia, tienen que observar y acatar, como se ha analizado anteriormente: 1) los derechos previstos en la Constitución: en la jerarquía formal que establece la Constitución, están desde las leyes orgánicas hasta los actos y decisiones de los poderes públicos, las normas que tienen que ser adecuadas a la Constitución; 2) Los tratados internacionales: cuando son normas más favorables, la Constitución y las demás normas deben adecuarse a esos derechos. 3) Los derechos que sean necesarios para garantizar la dignidad del ser humano o de las comunidades, pueblos y nacionalidades.

\section{v) El límite intangible de la adecuación normativa}

Hace alusión a la obligación que asumen los Estados a adecuar su ordenamiento jurídico interno adoptando las posición o interpretación más favorable. En otras palabras, los Estados están obligados a adecuar en su Derecho Nacional los derechos a los instrumentos jurídicos que establecen nuevos derechos o derechos 
más favorables a los reconocidos en la Constitución.

\section{b) El deber de adecuar los derechos en el Sistema Internacional (Interamericano) de Protección de Derechos Humanos}

El deber de adecuar las normas y las prácticas a los derechos se encuentra de forma clara y explícita en la Convención Americana de Derechos Humanos (en adelante, CADH), en cuyo artículo $2^{\circ}$ se establece lo siguiente:

"Si el ejercicio de los derechos y libertades mencionados en el artículo $1^{\circ}$ no estuviere ya garantizado por disposiciones legislativas o de otro carácter, los Estados Partes se comprometen a adoptar, con arreglo a sus procedimientos constitucionales y a las disposiciones de esta Convención, las medidas legislativas o de otro carácter que fueren necesarias para hacer efectivos tales derechos y libertades".

Del artículo 2 de la CADH y de las interpretaciones autorizadas que ha hecho la Corte IDH en relación con el deber de adecuación, se desprende: i) Las obligaciones internacionales que implican adecuar las normas y prácticas nacionales para optimizar derechos; ii) Las autoridades dentro del Estado obligadas a adecuar; iii) Los mecanismos jurídicos que los Estados deben utilizar para adecuar; iv) La oportunidad para adecuar; y, v) El fin de la adecuación.

\section{i) Las obligaciones internacionales que implican adecuar las normas y prácticas nacionales para optimizar derechos}

La obligación de adecuar las normas y prácticas nacionales es una obligación general, junto con la de respetar y proteger, que se encuentra en el artículo 1 de la Convención, que busca garantizar de forma efectiva todos los derechos reconocidos en la CADH. La Corte IDH en reiteradas ocasiones afirmó que esta obligación se deriva del derecho internacional. Así lo expuso en el Caso Garrido y Baigorria vs Argentina (1998: párrafo 68) y en el Caso Heliodoro Portugal vs Panamá (2008: párrafo 179):

"En el derecho de gentes, una norma consuetudinaria prescribe que un Estado que ha celebrado un convenio internacional, debe introducir en su derecho interno las modificaciones necesarias para asegurar la ejecución de las obligaciones asumidas".

La obligación de adecuar implica "el deber de los Estados Parte de organizar todo el aparato gubernamental $\mathrm{y}$, en general, todas las 
estructuras a través de las cuales se manifiesta el ejercicio del poder público, de manera tal que sean capaces de asegurar jurídicamente el libre y pleno ejercicio de los derechos humanos".

La modificación de las normas y prácticas en el derecho interno acorde a los estándares internacionales implica, a su vez, tres obligaciones: 1) Expulsar la norma del sistema jurídico o "suprimir toda norma contraria a la Convención"; 2) Interpretar las normas del derecho interno de manera conforme a los estándares internacionales de derechos humanos; y, 3) Aplicar y adecuar las prácticas en los Estados, aun cuando exista adecuación formal. Así lo expuso la Corte IDH en el Caso Almonacid Arellano y otros vs. Chile (2006: párrafo 201), Caso Mendoza y otros vs. Argentina (2017: párrafo 221) y Caso Radilla Pacheco vs. México (2009: párrafo 338).

"La existencia de una norma no garantiza por sí misma que su aplicación sea adecuada. Es necesario que la aplicación de las normas o su interpretación, en tanto prácticas jurisdiccionales y manifestación del orden público estatal, se encuentren ajustadas al mismo fin que persigue el artículo 2 de la Convención".

\section{ii) Las autoridades dentro del Estado obligadas a adecuar}

La Función Legislativa, como se ha firmado, es el obligado primario, pero no exclusivo ni siempre necesario.

Por la CADH y por sus interpretaciones, toda autoridad pública tiene mandato de aplicación directa y no necesariamente, para la aplicación de los derechos, se requiere una norma legal. La exigencia de reforma normativa podría afectar la vigencia y eficacia de los derechos. La exigencia legal, entendida como la intervención de la representación popular y democrática a través de la Función Legislativa, es imprescindible cuando se trata de restricción y limitación de derechos. En esos casos existe lo que se conoce como Reserva Legal. Pero cuando se trata de garantizar derechos y en particular de una obligación de ius cogens como es la igualdad y la no discriminación, y de proteger y garantizar derechos de grupos humanos discriminados o grupos vulnerables (por ejemplo, los migrantes indocumentados), que requiere de una especial protección, entonces la aplicación convencional es directa y no requiere necesariamente regulación legislativa. 


\section{iii) Los mecanismos jurídicos que los Estados deben utilizar para adecuar}

El artículo 2 de la CADH establece que, la Función Legislativa y demás autoridades competentes, deben hacer la adecuación "con arreglo a sus procedimientos constitucionales".

Ahora bien, si uno revisa el ordenamiento jurídico nacional es posible afirmar que en el Perú se puede adecuar el sistema jurídico a los derechos que se reconocen o se deriven de la CADH por varios caminos: la reforma constitucional de ser esta necesaria, la reforma legal, la interpretación constitucional, o la aplicación directa de la CADH y su materialización en todo acto de poder público (los actos administrativos del Poder Ejecutivo, por ejemplo).

Cualquiera de esos caminos tiene autoridades y competencias específicas. Así, la adecuación se puede llevar a cabo mediante la Función Legislativa, Función Ejecutiva, Función Jurisdiccional, o a través de la actuación de toda autoridad pública, como lo ha reconocido, por ejemplo, la Corte Constitucional del Ecuador en su Sentencia N 11-18-CN/19 (2019: párrafo 228).

Siendo ello así, queda claro que la $\mathrm{CADH}$, por ejemplo, hace una remisión al sistema jurídico interno de los países. En el Perú se puede hacer reformas a la Constitución, reformas legales, interpretaciones a la Constitución y a los tratados, aplicación directa de la CADH por el control de convencionalidad que llevan a cabo los órganos que ejercen función jurisdiccional, o, a través de la adecuada implementación de las recomendaciones hechas al Estado peruano a través de los organismos internacionales de protección de los derechos humanos.

\section{iv) La oportunidad para adecuar}

La oportunidad de la adecuación de los derechos requiere un análisis particular. En primer lugar, considerar si el reconocimiento y protección de los derechos humanos requiere siempre de una medida normativa (Reforma Constitucional y/o Legal); o si acaso, también es posible hacer lo mismo por medio de medidas jurisdiccionales o administrativas.

- La Reserva de Ley para reconocer y proteger derechos 
La Reserva de Ley es una garantía formal mediante la cual se considera que la Función Legislativa tiene competencia exclusiva para tratar una cuestión importante como la regulación de ciertos derechos. Además, es una garantía reforzada de los derechos y se encuentra claramente prevista para establecer delitos y penas y también para crear tributos. Se trata de una garantía, dentro de un estado democrático y de derechos, para evitar que de forma autoritaria se impongan cargas a las personas o restricciones indebidas a los derechos.

Cuando se trata del reconocimiento de derechos, del desarrollo de su contenido, del mejoramiento de las condiciones para el ejercicio o garantías de derechos, no se requiere reserva legislativa o desarrollo normativo. Por ello, la doctrina constitucional contemporánea y la propia Constitución, considera que los derechos serán de inmediata y directa aplicación. De lo contrario, como afirma Landa Arroyo (ver su libro "La Convencionalización del Derecho Peruano": 2016) los derechos no serían exigibles, no tendrían efecto útil, no podrían ser ejercidos por sus titulares. De exigirse siempre Reserva de Ley, se establecería una condición inadecuada que tornaría inútil el reconocimiento constitucional de derechos.

Sobre lo expuesto, es importante hacer algunas precisiones. La primera es que no es necesaria una reforma constitucional y/o legal para reconocer y proteger derechos sino que basta considerar, por el bloque de constitucionalidad y por una interpretación sistemática, evolutiva e integral, que el texto de la Constitución se complementa con el de la CADH y otros instrumentos internacionales, cuyo contenido y alcances han sido interpretados por la Corte IDH o por Órganos de Tratados de Derechos Humanos de Naciones Unidas como los que han formulado recomendaciones al Estado peruano.

La segunda es que una reforma constitucional y/o legal para reconocer derechos es conveniente pero no siempre necesaria. Cuando los derechos han sido reconocidos en instrumentos internacionales o por un órgano con competencia y autoridad para interpretarlos, el reconocimiento en el texto constitucional y/o legal no resulta indispensable.

Con lo cual, la reforma constitucional y /o legal no es un requisito previo para la vigencia o el goce efectivo de los derechos sin discriminación, más cuando existen medidas alternativas que garantizan la tutela de los derechos, como lo ha reconocido, por 
ejemplo, la Corte Constitucional del Ecuador en su sentencia $\mathrm{N}^{\circ} 11$ 18-CN/19 (2019: párrafo 244).

\section{- Otras medidas para reconocer y proteger derechos}

Sobre este punto, la propia Corte IDH, en un caso en que consideró que un Estado debía modificar su Constitución para adecuar a la CADH y a la interpretación de la Corte IDH, decidió que "El Estado debe modificar su ordenamiento jurídico interno, en un plazo razonable".

No obstante, lo antes señalado, la Corte IDH "instó a los Estados a que impulsen realmente y de buena fe las reformas legislativas, administrativas y judiciales", lo que quiere decir que reconoce que para aplicar la interpretación auténtica de la CADH no se requiere exclusivamente reformas legislativas, sino que pueden ser adecuaciones administrativas y judiciales; y que también, en todos esos mecanismos, se pueden presentar dificultades institucionales.

El momento de adecuación normativa, de facto, cuando se produjeren hechos que puedan considerarse actos por aplicación de normas o de interpretaciones inconstitucionales, es el momento en que tiene que tomarse la decisión.

Si la decisión se basa en una norma o en una interpretación que pueda generar una diferencia de trato, basado en una categoría sospechosa y que restringa o anule el ejercicio de un derecho, si no hay una justificación razonable, estamos sin duda alguna ante una discriminación, aún si no se ha adecuado la Constitución o las normas secundarias; es decir, estaríamos ante una violación de derechos fundamentales, así quedó establecido en el Caso Olmedo Bustos y otros vs. Chile, también conocido como "La última tentación de Cristo" (2001: punto resolutivo 4).

En esa misma línea, Tribunales y Cortes Constitucionales de la región han señalado claramente que las autoridades administrativas, al resolver los procesos sometidos a su conocimiento, se encontraban y se encuentran obligados a aplicar directa e inmediatamente la Constitución en su sentido material; este concepto incluye el texto constitucional, los instrumentos internacionales en materia de derechos humanos.

Lo dicho implica, tomando como base lo expuesto por la Corte 
Constitucional del Ecuador en la Sentencia Nº 098-17-SEP-CC, que autoridades administrativas, como en este caso MIGRACIONESestán en el deber inexcusable de interpretar toda la normativa que les corresponde aplicar, a la luz de las normas que componen la Constitución material.

Entonces, por lo antes expuesto, es posible afirmar que, por el control de constitucionalidad y de convencionalidad, toda autoridad pública (incluyendo a los organismos técnicos especializados como MIGRACIONES) está obligada a aplicar las normas constitucionales, las convencionales y las que se reconocen en los instrumentos internacionales de derechos humanos.

\section{v) El fin de la adecuación}

Por último, luego de lo expuesto, podemos afirmar que la finalidad de la adecuación, según el artículo $2^{\circ}$ de la $\mathrm{CADH}$, es realizar todas las reformas e interpretaciones en el sistema jurídico interno "que fueren necesarias para hacer efectivos tales derechos y libertades". No es la adecuación por el mero cambio normativo ni a través de un procedimiento legislativo, sino hacer efectivos los derechos, de ahí la necesidad de adecuar de la manera más eficiente y oportuna.

Visto así, resulta claro que la adecuación es un medio para lograr el ejercicio de derechos. Esos medios, por el margen de apreciación que tienen los Estados, son de libre configuración constitucional. Pero el fin está claro y no es negociable democrática o soberanamente por los Estados. En este sentido, si un medio no es adecuado para lograr el fin de respetar y garantizar derechos, simplemente no puede ni debe ser utilizado. El medio tiene que ser efectivo: legislativos, jurisdiccionales o administrativos, dependiendo del caso concreto.

No obstante, lo antes señalado, es fundamental dejar en claro que el deber de adecuar el sistema jurídico interno a los derechos y estándares internacionales de derechos humanos cuando fueren más favorables, no se agota con las reformas normativas. La exigencia internacional también es el cambio en las prácticas. Ello es así, ya que en las prácticas nos encontramos con estereotipos, con tradiciones, intolerancia hacia las personas diversas que, con distintos grados de radicalización, acaban discriminando, "generando la xenofobia, por ejemplo, que impulsan crímenes de odio", y hasta llegar a violencias 
físicas tanto en el ámbito público como privado, como bien lo ha señalado la Corte IDH en la Opinión Consultiva OC/24-17 (2017: párrafo 47).

\subsection{El enfoque de Derechos Humanos y la Protección de los Grupos Vulnerables en las acciones implementadas por MIGRACIONES}

Al respecto, tomando en consideración lo expuesto en el punto anterior, corresponde dar cuenta de las acciones implementadas por MIGRACIONES, las mismas que han recogido el Enfoque de Derechos Humanos y la protección de los Grupos Vulnerables, acreditando el compromiso asumido por el Estado peruano de adecuar su sistema jurídico a los derechos, como parte de su Política Migratoria.

\section{a) MIGRACIONES y la Reforma Migratoria}

El 07 de diciembre de 2012, se publicó en el diario oficial El Peruano, el Decreto Legislativo $N^{\circ} 1130$, Decreto Legislativo, que como ya lo hemos señalado, creó MIGRACIONES como una nueva entidad con autonomía técnica, económica y administrativa. Uno de los aspectos más importante de la reforma migratoria en el Perú ha sido precisamente la incorporación del Enfoque de Derechos humanos que implica que el Estado promueva y proteja los derechos humanos de las personas extranjeras, al igual que los del resto de la población nacional.

Pero es el año 2016 en el que MIGRACIONES inicia un verdadero proceso de reestructuración que ha permitido modernizar la gestión migratoria mediante la reforma de procesos, procedimientos, protocolos y trámites que buscan brindar servicios de calidad a los usuarios, así como atender, en lo que corresponde a sus funciones legales y estatutarias, el fenómeno migratorio, haciendo énfasis en las personas que forman parte de los denominados Grupos Vulnerables, creándose así el Equipo de Integración Migratoria, antes Equipo de Servicio al Migrante en Situación de Vulnerabilidad, cuyo nacimiento se formaliza el año 2018, mediante Resolución de Superintendencia $N^{\circ} 117-2018$-MIGRACIONES, de fecha 05 de abril de 2018.

b) El Equipo de Integración Migratoria y los Grupos Vulnerables

En principio, MIGRACIONES identificó la realidad de las mujeres extranjeras, madres de hijos peruanos, todas ellas con el común denominador de aspirar a una permanencia amable en nuestro país para proyectar bienestar en sus respectivos núcleos familiares. Las 
carencias y vicisitudes de dichas mujeres extranjeras empezaron a ser foco de atención para analizar en cada caso la procedencia de la condición de vulnerabilidad. A partir de ello, el análisis de la situación migratoria de cada extranjera, pasó de ser vista como un simple procedimiento administrativo, para convertirse en una oportunidad para colaborar con la búsqueda de soluciones para verdaderos dramas humanos, siempre en el marco del respeto por los tratados y convenios internacionales, la Constitución, las leyes y los reglamentos que forman parte del Ordenamiento Jurídico del Estado Peruano.

Fue así como MIGRACIONES, empezó a abordar esta problemática de manera progresiva, desde un Enfoque de Derechos Humanos, en general, y un Enfoque de Género, en especial. En esa línea, se dispuso la atención diferenciada a los y las migrantes, cuyo objetivo es identificar, diseñar e implementar propuestas de mejora para un servicio integral de las personas en situación de vulnerabilidad.

\section{c) El Permiso Temporal de Permanencia (PTP) y los Grupos Vulnerables}

En ese contexto, se impulsó ante el Ministerio del Interior la aprobación de la norma regulatoria del PTP, justamente para regularizar la situación migratoria de madres y padres extranjeros con hijas e hijos peruanos menores de edad o mayores de edad con discapacidad permanente. Esta medida se concretó a través de la aprobación del Decreto Supremo N 001-2017-IN, de fecha 2 de enero del 2017, convirtiéndose en la primera normativa especial con tales características en el país. Cabe precisar que esta norma incorporó una disposición especial para las víctimas de flagrante delito o con medidas de protección por delitos de violencia, pues desde la gestación del proyecto normativo se consideraba que estas personas merecían una atención diferenciada y, por ende, una especial protección por ser consideradas un Grupo Vulnerable.

Al mismo tiempo, desde MIGRACIONES se propuso un nuevo marco normativo migratorio nacional que recogiera el Enfoque de Derechos Humanos. Fue así como el 07 de enero de 2017, se publicó en el diario oficial El Peruano, el Decreto Legislativo $\mathrm{N}^{\circ}$ 1350, Decreto Legislativo de Migraciones y su Reglamento, aprobado por Decreto Supremo No 007-2017-IN, publicado en el diario oficial El Peruano el 29 de marzo de 2017, que incorpora diversos supuestos de vulnerabilidad y desarrolla las definiciones, responsabilidades y medidas migratorias de protección a las personas extranjeras 
en situación de vulnerabilidad, las mismas que fueron recogidas en el Título $X$ denominado "Personas Extranjeras en situación de vulnerabilidad" del referido Reglamento.

Además, ese mismo año, como ya lo hemos señalado, se aprobó la Política Nacional Migratoria dentro de la Mesa de Trabajo Intersectorial para la Gestión Migratoria, mediante el Decreto Supremo $N^{\circ}$ 015-2017-RE, publicado el 27 de abril de 2017 en el diario oficial El Peruano, que constituye el primer documento de política nacional en materia migratoria en la historia republicana del Estado peruano que enfatiza la posición del migrante como sujeto de derechos en igualdad de condiciones y sin discriminación que pueda afectarlo.

\section{d) El Enfoque de Derechos Humanos y la Protección de los Grupos Vulnerables para el Caso Especial de la Migración Venezolana}

En suma, es posible afirmar que la reforma de la gestión migratoria, la nueva legislación y las reformas institucionales, las mismas que han recogido el Enfoque de Derechos Humanos, han permitido atender el fenómeno del incremento del flujo migratorio de ciudadanos de nacionalidad venezolana al país; más aun tomando en cuenta que las cifras revelan que en el período 1994-2019 la migración creció exponencialmente, siendo posible apreciar dos intervalos en este proceso de incremento de la migración.

El primero que podríamos denominar la migración del buen momento del Perú, es decir, aquella que puede explicarse probablemente por las oportunidades que se abrían por el crecimiento peruano; $y$, el segundo intervalo migratorio que se da dentro de la misma tendencia positiva económicamente, pero se trastoca fuertemente por el llamado fenómeno venezolano, debido a la gran masa de migrantes que ingresaron y siguen ingresando al Perú, al punto de haberse convertido nuestro país en el segundo destino de venezolanos en el mundo, luego de Colombia.

La migración venezolana en el Perú ha sido masiva y se ha incrementado, sobre todo, desde el año 2018. Así, por ejemplo, el 2016 se asentaron 8,170 personas venezolanas en el Perú, 109,778 el 2017 y 660,780 el 2018. Ello demuestra un incremento del 502\% al 2017, llegando a 859,675 a la primera semana de agosto de 2019.

Como consecuencia de lo señalado, y en base al marco normativo de protección de personas extranjeras en situación de vulnerabilidad, 
MIGRACIONES ha implementado progresivamente medidas de regularización migratoria que buscan la integración delos extranjeros a la sociedad peruana, en clara consonancia con el Enfoque de Derechos Humanos y la Protección de Grupos Vulnerables.

\section{El Permiso Temporal de Permanencia (PTP)}

Entre estas medidas, podemos encontrar, por ejemplo, la aprobación del Decreto Supremo N 001-2017-IN; Decreto Supremo N0022017-IN, Decreto Supremo Nº023-2017-IN, Decreto Supremo N ${ }^{\circ}$ 001-2018-IN, y Decreto Supremo N 007-2018-IN, respectivamente, referidos a los lineamientos para el otorgamiento del PTP. Este marco normativo ha permitido que, entre febrero de 2017 y agosto de 2018, respectivamente, un total de 491,944 personas realizaran el trámite para la obtención del Permiso Temporal de Permanencia (PTP), documento que regulariza la situación migratoria por un año y permite desarrollar actividades en el marco de la legislación peruana, de los cuales, el 10\% son niños, niñas y adolescentes.

Tabla 1: Permiso Temporal de Permanencia tramitados por género y rango de edad entre febrero 2017-agosto del 2019.

\begin{tabular}{|c|c|c|c|c|}
\hline $\begin{array}{c}\text { RANGO } \\
\text { EDADES }\end{array}$ & MUJER & VARÓN & TOTAL & PORCENTAJE \\
\hline De 0 a 17 años & 24,075 & 25,519 & 49,594 & $10 \%$ \\
\hline De 18 a 29 años & 97,170 & 116,147 & 213,317 & $43 \%$ \\
\hline De 30 a 59 años & 92,282 & 131,736 & 224,018 & $46 \%$ \\
\hline De 60 a 59 años & 3,277 & 1,770 & 5,047 & $1 \%$ \\
\hline Total & $\mathbf{2 1 6 , 8 0 4}$ & $\mathbf{2 7 5 , 1 7 2}$ & $\mathbf{4 9 1 , 9 7 6}$ & $\mathbf{1 0 0} \%$ \\
\hline PORCENTAJE & $\mathbf{4 4 \%}$ & $\mathbf{5 6} \%$ & $\mathbf{1 0 0} \%$ & \\
\hline
\end{tabular}

\section{Acta de Permiso de Trabajo Extraordinario}

Asimismo, siguiendo una línea progresiva en la aplicación del Enfoque de Derechos Humanos y la Protección de Grupos Vulnerables, MIGRACIONES emitió el Acta de Permiso de Trabajo Extraordinario, documento que habilita al ciudadano venezolano a realizar actividades generadoras de renta de manera subordinada o independiente, por el plazo de sesenta (60) días calendario. Cabe precisar que estas medidas fueron desarrolladas mediante soluciones tecnológicas que hicieron y hacen posible la prestación de servicios 
en línea, entre estos, el permiso para firmar contratos, prórroga de permanencia, citas e inscripción en línea para migrantes, permiso de trabajo extraordinario, entre otros.

\section{Calidad Migratoria Especial}

Además, en atención a lo dispuesto en el artículo $230^{\circ}$ del citado Reglamento de la Ley de Migraciones, sobre medidas migratorias de protección- se vienen implementando otras medidas que incluyen el otorgamiento de la Calidad Migratoria Especial de manera excepcional a personas extranjeras en extrema situación de vulnerabilidad, así también, exoneración de multas y derechos de tramitación estipulados en la normatividad migratoria vigente y otros, que faciliten la atención a las circunstancias especiales de cada caso en concreto.

Es así que desde el año 2016 hasta julio de 2019, el Equipo de Integración Migratoria ha atendido un total de 24,624 personas extranjeras que han apelado a una situación de vulnerabilidad para acceder a diversos beneficios migratorios que explicamos a continuación.

Las atenciones se diferencian entre asesorías $u$ orientaciones, previas a la determinación de la situación de vulnerabilidad, y las atenciones de solicitudes concretas, que buscan la exoneración de pagos, requisitos y / o alguna medida de regularización de situación migratoria o de protección (Calidad Migratoria Especial o salida del país), entre otros.

Figura 1: Personas atendidas por Equipo de Integración Migratoria (2016-2019).

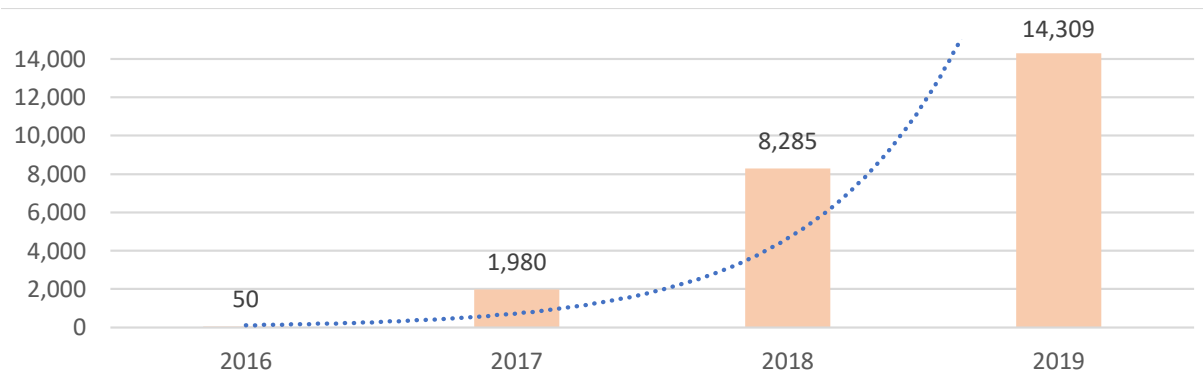

*Fuente: Estadísticas Equipo de Integración Migratoria - Gerencia Política Migratoria de la Superintendencia Nacional de Migraciones. Elaboración propia. Periodo de análisis: desde octubre 2016 a Julio 2019.

Como se puede apreciar en el gráfico 1, es evidente que el número 
de personas atendidas ha ido aumentado exponencialmente desde el año 2016. Así, en el año 2018, respecto al año 2017, se registró un incremento mayor al 300\%. Cabe advertir, que a mediados de este año ya hemos superado el total de atenciones del 2018.

Figura 2: Solicitudes atendidas por el Equipo de Integración Migratoria (20162019).

\begin{tabular}{|c|c|c|c|c|}
\hline 2,200 & & & & 1,967 \\
\hline 1,700 & & & 1,382 & \\
\hline 1,200 & & & 851 & \\
\hline 700 & & 497 & & \\
\hline 200 & 240 & & & \\
\hline-300 & & & & \\
\hline-500 & 2016 & 2017 & 2018 & 2019 \\
\hline De 0 a 17 años & 24 & 497 & 1,382 & 1,967 \\
\hline De 18 a más años & 0 & 250 & 851 & 1,224 \\
\hline
\end{tabular}

De 0 a 17 años De 18 a más años

*Fuente: Estadísticas Equipo de Integración Migratoria - Gerencia Política Migratoria de la Superintendencia Nacional de Migraciones. Elaboración propia. Periodo de análisis: desde octubre 2016 a Julio 2019

Como se puede observar en el gráfico 2, entre octubre del año 2016 a julio del año 2019, de las 24,624 atenciones registradas, 6,195 casos se concretaron en solicitudes de otorgamiento de medidas migratorias de protección.

De este universo, según sexo, se revela que la mayoría de solicitudes provino de hombres $(63,9 \%)$, respecto a las mujeres $(36,1 \%)$. Es importante destacar que el 65,5\% de estas atenciones corresponden al grupo etario de 0 a 17 años, presentando varias situaciones de vulnerabilidad (grave enfermedad, niño no acompañado, pobreza y pobreza extrema, situación migratoria irregular, otros), concurrentes con su condición de niño, niña y adolescente, respectivamente.

A su vez, corresponde advertir, que, según situación de vulnerabilidad, en el Cuadro $\mathrm{N}^{\circ} 02$ se observa que del total de solicitudes evaluadas entre enero del 2018 y julio del 2019, la mayoría, el $60.5 \%$, apela a la causal de vulnerabilidad de grave enfermedad, seguido de un $11,3 \%$ que expone la causal de niños, 
niñas y adolescentes, incluyéndose en este, a los niños, niñas y adolescentes no acompañados y separados. Es importante precisar, como se ha señalado anteriormente, que el grupo etario de 0 a 17 años, que representa el 65,5\% del total de solicitudes, además de presentar la causal de ser niños, niñas y adolescentes, exponen otros supuestos de vulnerabilidad.

La situación migratoria irregular es la tercera causal de vulnerabilidad más apelada, con un $11.2 \%$, y la cuarta, del $7.9 \%$, corresponde a pobreza y pobreza extrema, respectivamente.

Tabla 2: Grupos en situación de vulnerabilidad atendidos por el Equipo de Integración Migratoria (2018-2019).

\begin{tabular}{|lcccccc|}
\hline Supuesto de vulnerabilidad & 2018 & $\%$ & 2019 & $\%$ & Total & $\%$ \\
\hline Grave enfermedad & 1,243 & $55.9 \%$ & 1,304 & $65.6 \%$ & 2,547 & $60.5 \%$ \\
\hline Niñas, niños y adolescentes & 192 & $8.6 \%$ & 282 & $14.2 \%$ & 474 & $11.3 \%$ \\
\hline Pobreza y pobreza extrema & 178 & $8.0 \%$ & 156 & $7.9 \%$ & 334 & $7.9 \%$ \\
\hline $\begin{array}{l}\text { Situación migratoria } \\
\text { irregular }\end{array}$ & 340 & $15.3 \%$ & 132 & $6.6 \%$ & 472 & $11.2 \%$ \\
\hline Adultos mayores & 192 & $8.6 \%$ & 69 & $3.5 \%$ & 261 & $6.2 \%$ \\
\hline $\begin{array}{l}\text { Víctimas de violencia } \\
\text { familiar y sexual }\end{array}$ & 17 & $0.8 \%$ & 15 & $0.8 \%$ & 32 & $0.8 \%$ \\
\hline Mujeres embarazada & 29 & $1.3 \%$ & 12 & $0.6 \%$ & 41 & $1.0 \%$ \\
\hline Víctima de trata de personas & 17 & $0.8 \%$ & 3 & $0.2 \%$ & 20 & $0.5 \%$ \\
\hline $\begin{array}{l}\text { Personas con discapacidad } \\
\text { Ttras situaciones de }\end{array}$ & 12 & $0.5 \%$ & 5 & $0.3 \%$ & 17 & $0.4 \%$ \\
\hline $\begin{array}{l}\text { Total } \\
\text { vulnerabilidad }\end{array}$ & 2,223 & $0.1 \%$ & 9 & $0.5 \%$ & 12 & $0.3 \%$ \\
\hline
\end{tabular}

Respecto a las medidas migratorias de protección solicitadas entre el enero del 2018 y julio del 2019, se tiene el 72.9\% de las personas presentaron una solicitud relativa a la Calidad Migratoria Especial Residente. En el Cuadro $\mathrm{N}^{\circ} 03$ se detallan estas medidas solicitadas, siendo la Calidad Migratoria Especial Residente (62.4\%), condonación de multa por exceso de permanencia y otorgamiento de la Calidad Migratoria Residente (9.4\%), y celeridad de trámites de PTP $(9.2 \%)$ la mayor demanda en los grupos en situación de vulnerabilidad. 
Tabla 3: Medidas migratorias de protección solicitadas por personas extranjeras (2018-2019).

\begin{tabular}{|c|c|c|c|c|c|c|}
\hline Medidas solicitadas & 2018 & $\%$ & 2019 & $\%$ & Total & $\%$ \\
\hline $\begin{array}{l}\text { Calidad Migratoria Especial } \\
\text { Residente }\end{array}$ & 1,243 & $69.9 \%$ & 1,113 & $56.0 \%$ & 2,333 & $62.4 \%$ \\
\hline $\begin{array}{l}\text { Condonación de multa por } \\
\text { exceso de permanencia y } \\
\text { otorgamiento de la Calidad } \\
\text { Migratoria Especial } \\
\text { Residente }\end{array}$ & 170 & $9.6 \%$ & 183 & $9.2 \%$ & 353 & $9.4 \%$ \\
\hline $\begin{array}{l}\text { Celeridad de trámites de } \\
\text { PTP }\end{array}$ & 47 & $2.6 \%$ & 298 & $15.0 \%$ & 345 & $9.2 \%$ \\
\hline $\begin{array}{l}\text { Condonación de multa por } \\
\text { exceso de permanencia }\end{array}$ & 196 & $11.0 \%$ & 84 & $4.2 \%$ & 280 & $7.5 \%$ \\
\hline Exoneración de requisitos & 23 & $1.3 \%$ & 104 & $5.2 \%$ & 127 & $3.4 \%$ \\
\hline $\begin{array}{l}\text { Condonación de multa por } \\
\text { exceso de permanencia y } \\
\text { otorgamiento de Calidad } \\
\text { Migratoria Familiar } \\
\text { Residente }\end{array}$ & 17 & $1.0 \%$ & 96 & $4.8 \%$ & 100 & $2.7 \%$ \\
\hline Celeridad de trámites & 26 & $1.5 \%$ & 11 & $0.6 \%$ & 37 & $1.0 \%$ \\
\hline $\begin{array}{l}\text { Autorización de salida del } \\
\text { país, otros }\end{array}$ & 28 & $1.6 \%$ & 0 & $0.0 \%$ & 28 & $0.7 \%$ \\
\hline $\begin{array}{l}\text { Regularización de ingreso y } \\
\text { otorgamiento de la Calidad } \\
\text { Migratoria Especial } \\
\text { Residente }\end{array}$ & 2 & $0.1 \%$ & 20 & $1.0 \%$ & 22 & $0.6 \%$ \\
\hline $\begin{array}{l}\text { Prórroga de Calidad } \\
\text { Migratoria Especial } \\
\text { Residente }\end{array}$ & 4 & $0.2 \%$ & 16 & $0.8 \%$ & 20 & $0.5 \%$ \\
\hline No procedente & 21 & $1.2 \%$ & 62 & $3.1 \%$ & 83 & $2.2 \%$ \\
\hline Total & 1,777 & $100 \%$ & 1,987 & $100 \%$ & 3,741 & $100 \%$ \\
\hline
\end{tabular}

*Fuente: Estadísticas Equipo de Integración Migratoria - Gerencia Política Migratoria de la Superintendencia Nacional de Migraciones. Elaboración propia. Periodo de análisis:2018-2019.

Por último, es posible afirmar que MIGRACIONES viene impulsado, como se ha podido apreciar en los gráficos y cuadros expuestos previamente, una gestión migratoria que apuesta por la integración del migrante, garantizando la seguridad del control migratorio y los derechos humanos de los migrantes, siempre con un Enfoque de Derechos Humanos y otros (Enfoque de Género y Enfoque Diferencial, entre los más resaltantes). Para ello, en coordinación con otras Entidades del Estado, cooperación internacional y sociedad civil, viene promoviendo la prevención de toda forma de violencia y respeto a las expresiones e identidades culturales, promocionando 
los derechos y deberes de los ciudadanos extranjeros y atendiendo a migrantes en situación de vulnerabilidad a través de acciones y proyectos que favorecen la integración de los mismos a la sociedad peruana, siempre con Enfoque de Derechos Humanos y prestando atención a la protección de los Grupos Vulnerables.

\section{CONCLUSIONES}

Por lo antes expuesto, podemos concluir señalando lo siguiente:

3.1El Estado peruano ha recogido -a partir de 2017, sobre todo-el Enfoque de Derechos Humanos y la Protección de los Grupos Vulnerables en su Política Migratoria (Nacional y Sectorial Interna, respectivamente).

3.2El Estado peruano cuenta -a partir de 2017, sobre todo- con un marco normativo interno (constitucional, legal e infralegal) que ha servido para que el Poder Ejecutivo, a través de sus instituciones, diseñe políticas públicas que recogen el Enfoque de Derechos Humanos y la Protección de los Grupos Vulnerables en su Política Migratoria (Nacional y Sectorial Interna, respectivamente).

3.3El Estado peruano, respetuoso de sus obligaciones internacionales asumidas en materia de Derechos Humanos, a través del Poder Ejecutivo, ha diseñado políticas públicas que recogen el Enfoque de Derechos Humanos y la Protección de los Grupos Vulnerables en su política Migratoria (Nacional y Sectorial Interna, respectivamente) siempre observando el contenido y alcances de las decisiones jurisdiccionales, consultivas y observaciones generales, emitidas por la Corte IDH, Tribunal Constitucional peruano y Comité de los Derechos Humanos del Niño, por ejemplo.

3.4El Estado peruano, respetuoso de sus obligaciones internacionales en materia de Derechos Humanos, ha asumido el compromiso de adecuar su sistema jurídico a los Derechos Humanos, prueba de ello son las acciones implementadas por MIGRACIONES, Organismo Técnico Especializado adscrito al Sector Interior, a las que hemos hecho referencia en párrafos precedentes, las mismas que recogen el Enfoque de Derechos Humanos y la Protección de los Grupos Vulnerables en su gestión migratoria.

\section{RECOMENDACIONES}

Por lo antes expuesto, siguiendo la línea de pensamiento del profesor Luigi Ferrajoli, ex decano de la Facultad de Jurisprudencia de la Universidad 
Roma III, plasmado en un artículo titulado "Políticas contra los migrantes y crisis de la civilización jurídica", recomendamos respetuosamente tener en cuenta lo siguiente:

4.1Entender que la migración es un fenómeno de carácter estructural y, sobre todo irrefrenable, generado hoy en día por las desigualdades globales, la miseria creciente, las guerras, la pobreza y el hambre.

4.2En esa línea, Ferrajoli propugna instituir una ciudadanía universal, fundada en la humanidad que supere la dicotomía "derechos del hombre/derechos del ciudadano", y que reconozca -más allá de la pertenencia a un determinado Estado- como personas a todas las mujeres y hombres del mundo, y por lo mismo, poseedoras de los mismos derechos fundamentales. Se trata, en buena cuenta, de rechazar el concepto de ciudadanía como estatus privilegiado, anclado en la idea del Estado-Nación y resguardado por las "fronteras nacionales".

4.3Por último, Ferrajoli propone asumir el fenómeno migratorio como el auténtico hecho constitutivo del orden del futuro, destinado, como instancia y vehículo de igualdad, a revolucionar las relaciones entre los hombres y las mujeres, y a refundar, a largo plazo, el orden internacional. Perspectiva desde la cual el derecho de emigrar equivaldría al poder constituyente de este nuevo orden global, regido por un constitucionalismo mundial, establecido ya en la actualidad con las convenciones internacionales, aunque aún sin garantías que aseguren su efectividad.

\section{REFERENCIAS}

Landa, C. (2016). Convencionalización del Derecho Peruano. Palestra Editores. Lima.

Salmón, E. (2014). Curso de Derecho Internacional Público. Pontificia Universidad Católica del Perú. Lima.

Salmón, E. (2019). Introducción al Sistema Interamericano de Derechos Humanos. Pontificia Universidad Católica del Perú. Lima.

Saramago, J., (2009, viernes 17 de julio). Historias de la emigración. Otros cuadernos de Saramago (Blog) Recuperado de https://cuaderno. josesaramago.org/52205.html

Ley N²9158 - Ley Orgánica del Poder Ejecutivo. 
Decreto Legislativo $N^{\circ} 1266$ - Ley de Organización y Funciones del Ministerio del Interior.

Decreto Legislativo Nº 1350 - Decreto Legislativo de Migraciones.

Decreto Supremo 007-2017-IN - Reglamento del Decreto Legislativo 1350.

Decreto Legislativo $\mathrm{N}^{\circ} 1130$ - Decreto Legislativo que crea la Supertintendencia Nacional de Migraciones.

Decreto Supremo N 015-2017-RE - Aprueba la Política Nacional Migratoria 2017-2025.

Decreto Supremo $\mathrm{N}^{\circ}$ 001-2018-IN - Aprueban lineamientos para el otorgamiento del Permiso Temporal de Permanencia para las personas de nacionalidad venezolana.

Decreto Supremo $\mathrm{N}^{\circ}$ 007-2018-IN - Modifican Lineamientos para el otorgamiento del Permiso Temporal de Permanencia para las personas de nacionalidad venezolana, aprobados por Decreto Supremo $\mathrm{N}^{\circ} 001-$ 2018-IN.

Plan Nacional de Derechos Humanos (2018-2021).

Constitución Política del Perú (1993).

Ley $N^{\circ} 27444$-Ley de Procedimiento Administrativo General.

Tribunal Constitucional - Pleno Jurisdiccional Exp. N $^{\circ}$ 047-2004-AI/TC -Sentencia del Pleno Jurisdiccional de Tribunal Constitucional (del 24 de abril de 2006).

Declaración Universal de los Derechos Humanos.

Convención Internacional sobre los Derechos del Niño y la Niña.

Pacto Internacional de Derechos Civiles y Políticos.

Pacto Internacional de Derechos Económicos, Sociales y Culturales.

Fecha de recepción: 7 de agosto de 2019

Fecha de aceptación: 04 de octubre de 2019 